\title{
Capital Markets and the Instability of Open Economies*
}

\author{
by \\ Philippe Aghion \\ Harvard University, University College London, and CEPR \\ Philippe Bacchetta \\ Study Center Gerzensee, Université de Lausanne, and CEPR \\ and \\ Abhijit Banerjee \\ Massachusetts Institute of Technology
}

November 2000

* We are grateful to three anonymous referees, Beatriz Armendariz, Laura Bottazzi, Raquel Fernandez, Ed Glaeser, Urban Jerman, Jeffrey Nilsen, Hélène Rey, David Weil, and seminar participants at Harvard University, the Universitat Autònoma of Barcelona, and the LSE/FMG conference on market liquidity for comments on a previous draft. Pierre-Alain Bruchez provided excellent research assistance. Financial support from the MacArthur Foundation (Banerjee and Aghion) and the NSF (Banerjee) is gratefully acknowledged. 


\begin{abstract}
This paper introduces a framework for analyzing the role of financial factors as a source of instability in small open economies. Our basic model is a dynamic open economy model with a tradeable good produced with capital and a country-specific factor. We also assume that firms face credit constraints, with the constraint being tighter at a lower level of financial development. A basic implication of this model is that economies at an intermediate level of financial development are more unstable than either very developed or very underdeveloped economies. This is true both in the sense that temporary shocks have large and persistent effects and also in the sense that these economies can exhibit cycles. Thus, countries that are going through a phase of financial development may become more unstable in the short run. Similarly, in economies at an intermediate level of financial development, full capital account liberalization may destabilize the economy. On the other hand, foreign direct investment does not destabilize.
\end{abstract}




\section{Introduction}

This paper introduces a framework for analyzing the role of financial factors as a source of instability in small open economies. Our basic model is a dynamic open economy model with a tradeable good produced with internationally mobile capital and a countryspecific factor. Moreover, firms face financial constraints: the amount they can borrow is limited to $\mu$ times the amount of their current level of investible funds. ${ }^{1}$ A high $\mu$ then represents an effective and developed financial sector while a low $\mu$ represents an underdeveloped one.

Our model can provide some answers to a number of important and rather basic questions. First, we show that it is economies at an intermediate level of financial development - rather than the very developed or underdeveloped - that are the most unstable. This is true both in the sense that temporary shocks will have large and persistent effects and also in the sense that these economies can exhibit stable limit cycles. Thus, countries going through a phase of financial development may become more unstable in the short run.

Second, the model allows us to examine the effects of financial liberalization on the stability of the macroeconomy. Once again it turns out that the interesting economies are the ones at an intermediate level of financial development. In these economies, full financial liberalization (i.e., opening the domestic market to foreign capital flows) may actually destabilize, inducing chronic phases of growth with capital inflows followed by collapse with capital flight. On the other hand, foreign direct investment never destabilizes since foreign direct investors come in with their own credit - their ability to invest is

\footnotetext{
${ }^{1}$ The fact that firm level cash-flow is an important determinant of investment is now widely recognized even in the context of economies like the U.S. which have excellent financial markets. (e.g., see Hubbard (1998) or Bernanke, Gertler, and Gilchrist (1999)).
} 
unrelated to the state of the domestic economy. Overall, this suggests that economies at an intermediate stage of financial development should consider carefully how they liberalize their capital account. Allowing foreign direct investment while initially restricting portfolio investment may sometimes be a reasonable approach.

Third, our model allows us to assess the macroeconomic effects of specific shocks to the financial sector such as overlending by banks (leading to a phase of bank failures) or overreaction by investors to a change in fundamentals. ${ }^{2}$ Once again, our model predicts these shocks to have their most persistent effects when financial markets are at an intermediate stage of development.

The basic mechanism underlying our model is a combination of two forces: on one side, greater investment leads to greater output and ceteris paribus, higher profits. Higher profits improve creditworthiness and fuel borrowing that leads to greater investment. Capital flows into the country to finance this boom. At the same time, the boom in investment increases the demand for the country-specific factor and raises its price relative to the output good (unless the supply of that factor is extremely elastic). This rise in input prices leads to lower profits and therefore, reduced creditworthiness, less borrowing and less investment, and a fall in aggregate output. Of course, once investment falls all these forces get reversed and eventually initiate another boom. It is this endogenous instability which causes shocks to have persistent effects and in more extreme cases leads to limit cycles.

The reason why an intermediate level of financial development is important for this result is easy to comprehend: at very high levels of financial development, most firms' investment is not constrained by cash flow so shocks to cash flow are irrelevant. On the other hand, at very low levels of financial development, firms cannot borrow very much in any case and therefore their response to cash-flow shocks will be rather muted

\footnotetext{
${ }^{2}$ Perhaps as a consequence of herd behavior.
} 
- extra cash means more investment but only a little more. Therefore shocks will die out without causing any great turmoil. It is then at intermediate levels of financial development that shocks to cash flow will have an effect intense enough to be a source of instability.

This last argument also helps us understand why opening the economy to foreign capital may destabilize: essentially, the response of an economy with a closed capital market to a cash flow shock is limited since only so much capital is available to entrepreneurs. Additional funding sources in an open economy potentially increases the response to a shock and therefore the scope for volatility.

The basic mechanics of instability described here - an increase in input price leading to a profit squeeze and eventual output collapse - has been documented in a number of countries. For example, in the years leading up to the crisis of the early 1980's in the Southern Cone countries, there is evidence that profits in the tradeable sector sharply deteriorated due to a rise in domestic input prices (see Galvez and Tybout, 1985, Petrei and Tybout, 1985, or De Melo, Pascale and Tybout, 1985). Moreover, ample anecdotal evidence supports the impact of 'competitiveness' (e.g., a real appreciation) on the financial conditions of firms.

The dynamic impact of a liberalization predicted by the model is also consistent with the experience of several emerging market countries that have liberalized, in particular in Southeast Asia and Latin America, but also in some European countries. In the years prior to their respective crises, these economies had been going through a process of rapid financial sector liberalization, which facilitated borrowing by domestic firms. Partly as a result of this liberalization, capital flowed into these economies in large quantities, allowing rapid growth in lending and a boom in investment. However, episodes of large capital inflows have often been associated with growing imbalances, such as a 
real currency appreciation ${ }^{3}$, an increase in real estate prices (e.g., see Guerra de Luna, 1997), or an increase in non-performing loans (see World Bank, 1997, p. 255). When the crisis came, most of these forces got reversed - capital flowed out, the currency collapsed, real estate prices dropped, lending stopped, and investment collapsed. ${ }^{4}$

It is however important to emphasize that the goal of this paper is not to explain exactly what happened in some particular country, but rather to propose a unified macroeconomic framework that gives a central role to financial constraints and financial development. There are certainly a number of strands of the existing literature anticipating a significant part of what we have done here. The idea that financial constraints on firms can play a role in the propagation of the business cycle was modeled in Bernanke and Gertler (1989). Subsequent work by Kiyotaki and Moore (1997), Aghion, Banerjee, and Piketty (1999) and Azariadis and Smith (1998) have shown that these constraints can lead to oscillations, though only in the context of a closed economy. ${ }^{5}$ However none of these papers except Aghion, Banerjee, and Piketty (1999) focus on the level of financial development as a factor determining the extent of instability and none of them study the effects of opening up the domestic financial sector to foreign capital flows.

\footnotetext{
${ }^{3}$ See, for example, Calvo et al. (1996). The degree of real appreciation varies across countries; for example, it has been more pronounced in Latin America than in Asia.

${ }^{4}$ See World Bank (1997) and Milesi-Ferretti and Razin (1998) for systematic descriptions of the link between and capital flow reversals and currency crises. Moreover, Tornell (1998) claims that the degree of real exchange rate appreciation often determines the severity of the crisis. Gourinchas, Valdés, and Landerretche (1999) provide a systematic analysis of lending booms which coincide with movements in output, capital inflows, the current account and the real exchange rate that are fully consistent with our results. See also Honkapohja and Koskela (1999) for an illuminating description of the Finnish crisis of the 1990's, which fits well our analysis: first, an economic environment characterized by a large proportion of credit-constrained enterprises, for which investments are highly elastic w.r.t. current profits; second, a financial market deregulation in the 1980's that leads to a huge expansion of bank lending, to major inflows of foreign capital and to a sharp increase in real asset prices (in particular real estate prices) during the boom; and subsequently in the 1990's, a sharp fall in real asset prices, investments, and real GDP, and the occurrence of a banking crisis that eventually led to a tightening of banking regulations and to a devaluation of the Finnish currency after hopeless efforts to maintain a fixed exchange rate.

${ }^{5}$ Gertler and Rogoff (1990) study an open economy model with credit-market imperfections. However, they do not consider business cycle fluctuations.
} 
A separate literature focuses on the case for free capital mobility. Policy interest in the debate has been aroused by the recent, rather mixed, experience of a number of countries that have liberalized their capital account, ${ }^{6}$ but a number of important aspects, including the implications of liberalization on volatility, have not been widely studied. ${ }^{7}$ More importantly, none of these papers attempt to relate the effect of liberalization to the functioning of the domestic financial sector.

Finally a number of recent papers stress that specific shocks to the financial sector, such as those brought on by policy mistakes, herd behavior, panics, or corruption in the financial sector, may lead to crises in the real economy. While accepting the validity of these arguments, we feel these models suffer from ignoring some of the interactions between the financial sector and the rest of the economy. As our model makes clear, volatile behavior may arise even in the absence of such shocks; while on the other hand, the presence of such shocks does not automatically imply they will have large and persistent real effects.

The paper is organized as follows. Section 2 represents the core of the paper, with a description of the open-economy model and a characterization of the conditions under which macroeconomic volatility arises. Section 3 presents numerical simulations to assess the plausibility for volatility. Section 4 analyzes the impact of a capital account liberalization and contrasts the stabilizing effect of unrestricted FDI with the potentially destabilizing effects of either foreign indirect investments or restricted foreign direct investments. Section 5 describes various extensions and draws some tentative policy conclusions.

\footnotetext{
${ }^{6}$ See, for example, Johnston et al. (1997) or Eichengreen et al. (1998).

${ }^{7}$ Obstfeld (1986), McKinnon (1993), Bacchetta (1992), Bartolini and Drazen (1997) analyze capital account liberalizations. McKinnon and Pill (1997) and Bacchetta and van Wincoop (2000) are among the few examining the issue of volatility.
} 


\section{The Basic Mechanism}

For pedagogical purposes we consider first a simple model with constant saving rates and a Leontief technology involving a inelastic supply of the country-specific factor. We then extend our analysis, first to allow for an elastic supply of domestic input; second, to the more general case of a CES production technology; and third, to the case where saving decisions result from intertemporal utility maximization.

\subsection{A Simple Framework}

We consider a small open economy with a single tradeable good produced with capital and a country-specific factor. One should typically think of this factor as input services such as (skilled) labor or real estate. We take the output good as the numeraire and denote by $p$ the price of the country-specific factor when expressed in units of the output good. The relative price $p$ can also be interpreted as the real exchange rate. In this basic framework we assume that the supply of the country-specific factor is inelastic and equal to $Z$.

For the sake of presentation, in this subsection we also assume that all agents save a fixed fraction $(1-\alpha)$ of their total end-of-period wealth and thus consume a fixed fraction $\alpha$. This assumption will be relaxed in subsection 2.5 below. The intertemporal decisions of lenders are of no consequence for output in such an open economy since investors can borrow in international capital markets. They will, however, affect net capital flows. ${ }^{8}$

There are two distinct categories of individuals in the economy. First, the lenders who cannot directly invest in production, but can lend their initial wealth endowments

\footnotetext{
${ }^{8}$ Notice that the separation between the decisions of lenders and entrepreneurs does not imply separation between total national savings and investment. Gertler and Rogoff (1990) show that a framework with credit constraints can explain the high correlation between total savings and investment (Feldstein and Horioka, 1980). We obtain a similar result in our framework. However, in general this result also depends on lenders' savings behavior.
} 
at the international market-clearing interest rate $r$. Second, there are the entrepreneurs (or borrowers) who are the people who have the opportunity to invest in production. There is a continuum of lenders and borrowers and their number is normalized to one for both categories.

Output $y$ is given by the following production function:

$$
y=\min \left(\frac{K}{a}, z\right),
$$

where $1 / a>r$, i.e., we assume that productivity is larger than the world interest rate. $K$ denotes the current level of capital and $z$ denotes the level of the country-specific input. More general production functions will be introduced in section 2.4. With perfect capital markets, investment would simply be determined by the international interest rate $r$.

Credit-market imperfections: Due to standard agency (moral hazard) considerations, an entrepreneur with initial wealth $W_{B}$ can borrow at most $L=\mu W_{B}$. The presence of capital market imperfections implies that entrepreneurs cannot borrow up to the net present value of their project; they can only borrow an amount proportional to their current cash-flow (as in Bernanke-Gertler (1989)). The proportionality coefficient, or credit multiplier $\mu>0$, reflects the level of financial development in the domestic economy. In the extreme case where $\mu=0$, the credit market collapses and investors can only invest their own wealth. Higher values of $\mu$ correspond to higher levels of financial development.

A simple justification for relating the capital market to the level of financial development and basing it on moral hazard by the borrower, can be found in Holmstrom-Tirole (1996) and in Aghion-Banerjee-Piketty (1999). In general $\mu$ will depend on the rate of interest being charged, which in turn implies a constant credit multiplier in a model where the interest rate is given by the world capital markets. However, in section 4 and Appendix B we compare our basic model with a model with a closed capital market where the interest rate is endogenously determined by domestic investment demand and 
domestic savings supply. Yet, for convenience, we shall maintain the assumption of a $\mu$ that does not depend on the interest rate in that section as well. As shown in AghionBanerjee-Piketty (1999), this corresponds to a particular parametrization of the more general model of the credit market presented in that paper. Our results would only be stronger if we allowed the usual negative relation between the interest rate and $\mu$.

Production decision: Entrepreneurs with total initial wealth $W_{B}$ will choose the level of the country-specific factor $z$ [with corresponding investment $K=I-p \cdot z$ ] to maximize current profits. Given the above Leontief technology, the optimum involves $z=\frac{K}{a}$, so that:

$$
I-p \cdot z=a \cdot z
$$

There are two cases:

i) $Z>\frac{K}{a}$ so that there is an excess supply of the country-specific input. This immediately gives us $p=0$. Output at date $t$ is then given by:

$$
y^{t}=\frac{K^{t}}{a}=\frac{1}{a}(1+\mu) W_{B}^{t}
$$

ii) $Z \leq \frac{K}{a}$ so that there is excess demand for the immobile factor. Therefore $p>0$ and output is determined in equilibrium by the supply of the country-specific input: $y^{t}=Z$. From (2) and the definition of $I$, the equilibrium price of the country-specific input is given by:

$$
p^{t}=\frac{(1+\mu) W_{B}^{t}-a Z}{Z} .
$$

This equilibrium price, which is a positive function of $W_{B}$, is the key variable whose movements over time will produce volatility.

The Timing of Events: The timing of events within each period $t$ is the following. Investment, borrowing and lending, and the payment of the country-specific factor services $p \cdot Z$ by entrepreneurs to the owners of that factor, take place at the beginning of the period (which we denote by $t^{-}$). Everything else occurs at the end of the period 
(which we denote by $t^{+}$): the returns to investments are realized; borrowers repay their debt, $r L$, to lenders; and finally, agents make their consumption and savings decisions determining in turn the initial wealth of borrowers at the beginning of the next period (i.e., at $\left.(t+1)^{-}\right)$.

Dynamic Equations: Now that we have laid out the basic model, we can analyze the aggregate dynamics of the economy and in particular investigate why open economies with imperfect credit markets may experience macroeconomic volatility. Since both $I$ and $p$ depend on entrepreneurs' wealth $W_{B}$, output does too. Thus, output dynamics are determined by the evolution of entrepreneurs' behavior. Let $W_{B}^{t+1}$ denote the disposable wealth of entrepreneurs (borrowers) at the beginning of period $t+1$. The dynamic evolution of $W_{B}$ (and therefore of investment and total output) between two successive periods is simply described by the equation:

$$
W_{B}^{t+1}=(1-\alpha)\left[e+y^{t}-r \mu W_{B}^{t}\right]
$$

where $e$ is an exogenous income in terms of output goods, $y^{t}=\min \left(\frac{I}{a}, Z\right)$ is output in period $t$ (also equal to the gross revenues of entrepreneurs during that period). The expression in brackets is the net end-of-period $t$ revenue of entrepreneurs. The net disposable wealth of entrepreneurs at the beginning of period $t+1$ is what remains of this net end-of-period return after consumption, hence the multiplying factor $(1-\alpha)$ on the right-hand-side of equation (4).

Entrepreneurs invest and borrow only if their profits are larger than or equal to the international return. When $\mu$ or $W_{B}$ are large, entrepreneurs invest only up the point where $y-r L=r W_{B}$. Any remaining wealth is invested at the international market rate. In this case, no pure profits are earned from production and the evolution of wealth is simply given by:

$$
W_{B}^{t+1}=(1-\alpha)\left[e+r W_{B}^{t}\right]
$$

Thus, the dynamics are fully described either by difference equation (4) or by differ- 
ence equation (5).

\subsection{Volatility}

When the dynamic evolution of domestic entrepreneurs' wealth is described by equation (4), an increase in entrepreneurs' wealth $W_{B}^{t}$ at the beginning of period $t$ has an ambiguous effect on next period's wealth $W_{B}^{t+1}$. This is due to the fact that the amount of invested wealth itself depends negatively on the input price $p$, whilst $p$ depends positively on current wealth. Using the fact that:

$$
\left(a+p^{t}\right) y^{t}=(1+\mu) W_{B}^{t},
$$

we have:

$$
\frac{d y^{t}}{d W_{B}^{t}}=\frac{(1+\mu)}{a+p^{t}}-\frac{y^{t}}{a+p^{t}} \frac{\partial p^{t}}{\partial W_{B}^{t}}
$$

Then, from (4), the impact of last period wealth on current end of period wealth can be decomposed into two effects:

$$
\frac{d W_{B}^{t+1}}{d W_{B}^{t}}=(1-\alpha)[\underbrace{\frac{1+\mu}{a+p^{t}}-r \mu}_{\text {wealth effect }}-\underbrace{\frac{y^{t}}{a+p^{t}} \frac{\partial p^{t}}{\partial W_{B}^{t}}}_{\text {price effect }}]
$$

On the one hand, there is a positive wealth effect of current wealth on future wealth: for a given price of the country-specific factor $p^{t}$, a higher inherited wealth $W_{B}^{t}$ from period $(t-1)$ means a higher level of investment $(1+\mu) W_{B}^{t}$ in period $t$ which, all else equal, should produce higher revenues and thus higher wealth $W_{B}^{t+1}$ at the beginning of period $t+1$. On the other hand, there is a negative price effect of current wealth on future wealth: more investment in period $t$ also implies a greater demand for the country-specific factor to thus raise its price $p^{t}$ during that period. This, in turn, has a detrimental effect on period $t$ revenues and therefore on the wealth $W_{B}^{t+1}$ at the beginning of period $t+1$.

With the above Leontief specification, the price effect is eliminated whenever the current wealth $W_{B}^{t}$ is so small that current investment cannot absorb the total supply 
of the country-specific factor. In this case $p^{t} \equiv 0$ and:

$$
W_{B}^{t+1}=(1-\alpha)\left[e+\left\{\frac{1+\mu}{a}-r \mu\right\} W_{B}^{t}\right]
$$

so that $d W_{B}^{t+1} / d W_{B}^{t}>0$.

On the other hand, the price effect dominates when the current wealth $W_{B}^{t}$ is sufficiently large that current investment exhausts the total supply of the country-specific factor. In this case, we simply have:

$$
W_{B}^{t+1}=(1-\alpha)\left[e+Z-r \mu W_{B}^{t}\right]
$$

so that $d W_{B}^{t+1} / d W_{B}^{t}<0$.

Figure 1 shows the relationship between $W_{B}^{t+1}$ and $W_{B}^{t}$ in this basic Leontief setup. This relationship is represented by three segments. The first one is the upward sloping curve described by (6) for $W<\underline{W}=\frac{a Z}{1+\mu}$; this is the case where the wealth effect dominates as $p=0$. The second segment, for $\underline{W}<W<\bar{W}=\frac{Z}{(1+\mu) r}$, is described by (7); in this case, the price effect always dominates. Finally, the third segment $(W>\bar{W})$ represents equation (5) where entrepreneurs are not credit-constrained. As drawn in the figure, the $45^{\circ}$ line intersects the $W_{B}^{t+1}\left(W_{B}^{t}\right)$ curve at the point $\widehat{W}$ which lies in the second segment. This intersection can also be in either of the other two segments. It will be in the first segment when $\frac{(1-\alpha) e}{1-(1-\alpha)\left\{\frac{1+\mu}{a}-r \mu\right\}}$, the fixed point of equation (6), is less than $\underline{W}$. Since $\frac{(1-\alpha) e}{1-(1-\alpha)\left\{\frac{1+\mu}{a}-r \mu\right\}}$ is increasing in $\mu$ while $\underline{W}$ is decreasing, it is clear that this can only happen when $\mu$ is very small. On the other hand, the intersection will be in the third segment when the fixed point of equation $(5), \frac{(1-\alpha) e}{1-(1-\alpha) r}>\bar{W}=\frac{Z}{(1+\mu) r}$. This will only happen when $\mu$ is sufficiently large. For intermediate values of $\mu$, corresponding to an intermediate level of financial development, the case is depicted in Figure 1, the one case where the economy does not converge monotonically to its steady state.

In this case there are two possibilities - short run fluctuations, represented by oscillations that eventually converge to the steady state, $\widehat{W}$, and long run volatility, represented 
by a system which does not converge to a steady state but instead continues to oscillate forever. A necessary condition for the existence of such a limit cycle is that the steady state at $\widehat{W}$ be unstable, true only when the slope of the $W_{B}^{t+1}\left(W_{B}^{t}\right)$ schedule at $\widehat{W}$ is less than -1 , corresponding to when $\widehat{W}$ lies in the second segment of that schedule. Thus, for long run volatility to occur, we must have $\underline{W}<\widehat{W}<\bar{W}$ and $-(1-\alpha) \mu r<-1$.

If these conditions hold, one can easily derive additional sufficient conditions under which long-run volatility actually occurs. For example, a two-cycle $\left(W_{1}, W_{2}\right)$ will satisfy: ${ }^{9}$

$$
W_{1}=\frac{(1-\alpha)(e+Z)}{1+r \mu(1-\alpha)^{2}\left(e+\frac{1+\mu}{a}-r \mu\right)} ; \quad W_{2}=\frac{(1-\alpha)^{2}\left(e+\frac{1+\mu}{a}-r \mu\right)(e+Z)}{1+r \mu(1-\alpha)^{2}\left(e+\frac{1+\mu}{a}-r \mu\right)}
$$

with $W_{1}<\underline{W}<W_{2}<\bar{W}$. This two-cycle will be stable whenever $(1-\alpha)^{2} r \mu\left(\frac{1+\mu}{a}-r \mu\right)<$ 1. Conditions for the existence of longer (and more plausible) cycles can be derived using standard techniques. The dynamic simulations will show that the fluctuations can be complex since wealth can fluctuate between the constrained (the first two segments in Figure 1) and the unconstrained (the third segment) regions.

Intuitively, the basic mechanism underlying this cyclicality can be described as follows: during a boom the demand for the domestic country-specific factor goes up as (high yield) investments increase, thus raising its price. This higher price will eventually squeeze investors' borrowing capacity and therefore the demand for country-specific factors. At this point, the economy experiences a slump and two things occur: the relative price of the domestic factor collapses, while a fraction of the factor available remains unused since there is not enough investment. The collapse in the factor price thus corresponds to a contraction of real output. Of course, the low factor price will eventually lead to higher profits and therefore to more investment. A new boom then begins.

\footnotetext{
${ }^{9}$ This follows immediately from the equations:

$$
\begin{aligned}
& W_{1}=(1-\alpha)\left(e+Z-r \mu W_{2}\right) \\
& W_{2}=(1-\alpha)\left(e+\frac{1+\mu}{a}-r \mu\right) W_{1} .
\end{aligned}
$$
}


The reason why the level of financial development matters is also quite intuitive: economies at a low level of financial development have low levels of investment and do not generate enough demand to push up the price of the country specific factor while economies at a very high level of development have sufficient demand for that factor to keep its price positive.

\subsection{The Leontief Case with an Elastic Supply of the Country- Specific Factor}

In the previous subsection, there were no output fluctuations when $p>0$ because of the combination of a Leontief technology and a fixed supply of the domestic input. In this subsection, we relax the assumption of a fixed supply of the country-specific factor and show output fluctuations with a Leontief technology. Assume that $Z$ is instead produced by (domestic) lenders using the tradeable good at a cost $c(Z)=\varphi Z^{\nu}$, where $\nu>1$. Maximization of a domestic lender's profit $p Z-\varphi Z^{\nu}$, yields the optimal supply of the country-specific factor:

$$
Z=\left(\frac{p}{\varphi \nu}\right)^{\frac{1}{\nu-1}}
$$

Thus, we have $p>0$ when there is production. This, together with the equation $(p+a) y^{t}=(1+\mu) W_{B}$, implies that the equilibrium price $p$, such that $y^{t}=Z$, must satisfy the equation :

$$
(p+a)\left(\frac{p}{\varphi \nu}\right)^{\frac{1}{\nu-1}}=(1+\mu) W_{B}
$$

This equation determines $p$ and $Z$ as positive functions of $(1+\mu) W_{B}$ The dynamic evolution of wealth, described by the equation:

$$
W_{B}^{t+1}=(1-\alpha)\left[e+Z^{t}-r \mu W_{B}^{t}\right]
$$

can thus be reexpressed as a dynamic equation in $p^{t}$, namely:

$$
\theta\left(p^{t+1}, \nu\right)=(1-\alpha)\left[e+\left(\frac{p^{t}}{\varphi \nu}\right)^{\frac{1}{\nu-1}}-r \mu \theta\left(p^{t}, \nu\right)\right]
$$


where $\theta\left(p^{t}, \nu\right)=W_{B}^{t}=\frac{\left(p^{t}+a\right)\left(\frac{p^{t}}{\varphi \nu}\right)^{\frac{1}{\nu-1}}}{(1+\mu)}$.

Equation (11) implicitly defines a schedule $p^{t+1}\left(p^{t}\right)$, and we are interested in whether this schedule generates dynamics similar to those arising with an inelastic supply of the country specific factor. It is convenient for this purpose to set $e=0 ;{ }^{10}$ under this additional assumption, the steady state value of $p$ is:

$$
p^{*}=\frac{(1-\alpha)(1+\mu)}{1+(1-\alpha) r \mu}-a .
$$

As before, the dynamic behavior of the system depends crucially on the slope of the $p^{t+1}\left(p^{t}\right)$ schedule at $p^{t}=p^{*}$. When this slope is greater than -1 the system converges to the steady state. Otherwise it oscillates permanently (though it may or may not converge to a stable cycle). A sufficient condition for the system to display long run volatility (in the form of permanent oscillations) is that

$$
\left.\frac{d p^{t+1}}{d p^{t}}\right|_{\left(p^{t}=p^{*}\right)}=(1-\alpha)\left[\frac{1+\mu}{\nu p^{*}+a}-r \mu\right]=\Lambda(\nu)<-1 .
$$

Clearly for $\nu$ large enough, this condition will hold as long as $(1-\alpha) r \mu>1$. Note that this is also the condition for oscillations in the case where the supply of the input is completely inelastic, which is what we would expect. ${ }^{11}$

The fact that the supply function must be somewhat inelastic to generate volatility should be intuitive. In the case where supply is perfectly elastic $(\nu=1)$ the factor price equals its marginal cost, so there is no price effect. It remains to check whether the conditions for sustained volatility are empirically plausible. We assert that they are, but postpone the actual discussion of this issue until the next section.

\footnotetext{
${ }^{10}$ The assumption of a zero endowment does not affect the existence of cycles, but it does affect the comparative statics with respect to $\mu$.

${ }^{11}$ In particular, using Grandmont (1988, Proposition C.3.1), we know that a sufficient condition to obtain a Flip bifurcation and thereby the existence of stable two-cycles in this model, is that: (i) for some $\nu^{*} \in(1, \infty)$, we have: $\Lambda(\nu=1)>-1=\Lambda\left(\nu^{*}\right)>\Lambda(\nu=\infty)$; (ii) the third derivative of the $p^{t+1}\left(p^{t}\right)$ function for $\nu=\nu^{*}$ at $p=p^{*}$ is not zero; (iii) for all $p^{t} \leq p^{*}, p^{t+1}\left(p^{t}\right)$ remains in the parameter region where the credit constraint is binding. Whilst (ii) is generically satisfied, showing that (iii) actually holds for a non-empty set of parameter values that includes a neighbourhood of the bifurcation point $\nu^{*}$, is hard to do analytically, but can be done through simulations.
} 
Note that there are no oscillations when $\mu$ is close to 0 , since $\left.\frac{d p^{t+1}}{d p^{t}}\right|_{\left(p^{t}=p^{*}\right)}$ is always positive in that case. Also, the economy will not fluctuate when domestic entrepreneurs are not credit-constrained (i.e., when $\mu$ is sufficiently large), since domestic investment and output are then independent of current entrepreneurs' wealth. It is again only for intermediate values of $\mu$, i.e., in economies at an intermediate level of financial development, that endogenous fluctuations will occur.

\subsection{CES Technology}

Here, we extend the analysis in subsection 2.2 to the more general case where the production function $f(K, z)$ is of the CES type, with $f(K, z)=A\left(K^{\theta}+\gamma z^{\theta}\right)^{1 / \theta}$, with $A>r$ and $\gamma>0 .{ }^{12}$ The parameter $\theta$ determines the elasticity of substitution between $K$ and $z$ (we assume $\theta<1$ for concavity). This CES specification includes as special cases, both the Cobb-Douglas technology when $\theta=0$, and a Leontief technology when $\theta \rightarrow-\infty$.

Now we show in Appendix A that aggregate output at date $t$, which, for given total investment $I^{t}$ is defined as:

$$
y^{t}=\max _{z} f(\underbrace{I^{t}-p^{t} \cdot z}_{K}, z),
$$

can simply be reexpressed as:

$$
y^{t}=\psi\left(p^{t}\right) \cdot I^{t}
$$

where

$$
\psi\left(p^{t}\right)=A \cdot \phi^{\frac{1-\theta}{\theta}}
$$

and $\phi=1+\left(p^{t}\right)^{\frac{\theta}{\theta-1}} \gamma^{\frac{1}{\theta-1}}$. In addition the condition that the market for the domestic input clears requires: ${ }^{13}$

$$
z=\frac{\left(\frac{p}{\gamma}\right)^{\frac{1}{\theta-1}} I}{\phi}=Z .
$$

\footnotetext{
${ }^{12}$ This is to make sure that it pays to produce at least some times and that the country-specific factor is used.

${ }^{13}$ See Appendix A.
} 
As long as $\psi\left(p^{t}\right)>r$, agents invest up to their credit limit, implying that $I^{t}=$ $(1+\mu) W_{B}^{t}$. Using this we can rewrite the market-clearing condition for the country specific factor as

$$
\frac{\left(\frac{p}{\gamma}\right)^{\frac{1}{\theta-1}}(1+\mu) W_{B}^{t}}{\phi}=Z .
$$

This can be rewritten in the form $\frac{(1+\mu) W_{B}^{t}}{p+\left(\frac{p}{\gamma}\right)^{\frac{1}{1-\theta}}}=Z$, from which it follows that since $\theta<1$, $p^{t}$ is increasing in $(1+\mu) W_{B}^{t}$. This gives a price effect of current wealth on future wealth which is proportional to $1+\mu$. However, there is an upper bound to the price level given by $\psi\left(p^{t}\right)=r$, the point where entrepreneurs stop investing in their project.

Turning next to the $W_{B}^{t+1}\left(W_{B}^{t}\right)$ curve itself, it is useful to define $\bar{W}$ as the value of $W_{B}$ for which $\psi\left(p^{t}\right)=r$. Then for $W_{B}<\bar{W}$, since $\psi\left(p^{t}\right)>r$, we have $I^{t}=(1+\mu) W_{B}^{t}$, which allows us to rewrite equation (4) as

$$
W_{B}^{t+1}=(1-\alpha)\left[e+\left\{(1+\mu) \psi\left(p^{t}\right)-r \mu\right\} W_{B}^{t}\right]
$$

In Appendix A we show that the $W_{B}^{t+1}\left(W_{B}^{t}, \theta\right)$ curve is single-peaked and slopes downward for high enough values of $W_{B}^{t}$, at least for $\theta<0$. For $W_{B}>\bar{W}$, the relevant dynamics are given by equation (5) as in the Leontief case, and the $W_{B}^{t+1}\left(W_{B}^{t}, \theta\right)$ curve slopes upward. The curve therefore has the reversed and side-ways S-shape we found in the Leontief case.

The question now is whether the price effect is strong enough to generate long run volatility (this, it will be recalled, requires that $\frac{d W_{B}^{t+1}}{d W_{B}^{t}}<-1$ at the steady-state point $\widehat{W}$ where $\left.W_{B}^{t+1}(\widehat{W}, \theta)=\widehat{W}\right) \cdot{ }^{14}$ In Appendix A we show that when the dynamics are described by equation (4), i.e., for $W_{B}^{t}<\bar{W}$, then:

$$
\frac{d W_{B}^{t+1}}{d W_{B}^{t}}=(1-\alpha)\left[\frac{(1+\mu) \psi(p)}{\phi(p)(1-\theta)+\theta}-r \mu\right]
$$

\footnotetext{
${ }^{14}$ In what follows we implicitly assume that $\widehat{W}<\bar{W}$, which in turn is true for a whole range of parameter values, in particular for the values we use in the simulations presented in the next section.
} 
Recall that $\phi=1+\left(p^{t}\right)^{\frac{\theta}{\theta-1}} \gamma^{\frac{1}{\theta-1}}$ and $\psi\left(p^{t}\right)=A \cdot \phi^{\frac{1-\theta}{\theta}}$. When $\theta$ goes to $-\infty, \frac{\theta}{\theta-1}$ goes to 1 and $\gamma^{\frac{1}{\theta-1}}$ goes to 1 . It follows that for any fixed $p$, as $\theta$ goes to $-\infty, \frac{d W_{B}^{t+1}}{d W_{B}^{t}}$ goes to $-(1-\alpha) r \mu .^{15}$ This suggests that under the assumption made above, that is $-(1-\alpha) r \mu<-1$, when $\theta$ is negative enough it is possible to get long run volatility. ${ }^{16}$ Moreover, it can be easily seen that the price effect can dominate only for intermediate values of $\mu$ : the expression in (13) is strictly positive for $\mu=0$, while there is no price effect for $\mu$ large since the upper bound on $p\left(\psi\left(p^{t}\right)=r\right)$ becomes binding.

The more interesting question is however whether the conditions for long-run volatility are empirically reasonable. While dynamic simulations are left for the next section, Figure 2 presents an example of the $W_{B}^{t+1}\left(W_{B}^{t}, \theta\right)$ curve assuming $\mu=4, \theta=-4$, and $e=0$ (the other parameters are as defined in the simulation of Section 3). It can be verified that starting from any value $W_{B}^{t}$ (except the point where the curve intersects the $45^{\circ}$ line) the system will not converge to a steady state.

\subsection{Optimal Savings by Entrepreneurs}

The savings rate of entrepreneurs has so far been maintained constant at $1-\alpha$. A natural question is whether there could still be long-run volatility when the savings rate is derived from the usual inter-temporal maximization problem. In this section

\footnotetext{
${ }^{15}$ This is what we would expect, since the case where $\theta=-\infty$ corresponds to the Leontief case and we already saw that in that case, $\frac{d W_{B}^{t+1}}{d W_{B}^{t}}=-(1-\alpha) r \mu$.

${ }^{16}$ More specifically, if $(1-\alpha) r \mu>1$, we have:

$$
\Delta(\theta=0)>0>-1>\Delta(\theta=-\infty),
$$

where $\Delta(\theta)$ denotes the value of the slope $\frac{d W_{B}^{t+1}}{d W_{B}^{t}}$ at the steady-state defined by the intersection between the $45^{\circ}$ line and the $W_{B}^{t+1}\left(W_{B}^{t}, \theta\right)$ schedule. Then, let $\theta^{*}$ be defined by:

$$
\Delta\left(\theta^{*}\right)=-1
$$

(such as $\theta^{*}$ exists by continuity of $\frac{d W_{B}^{t+1}}{d W_{B}^{t}}$ with respect to $\theta$ ). Then, using Grandmont (1988, Proposition C.3.1 on Flip Bifurcations) we know that if: (i) the third derivative of $W_{B}^{t+1}\left(W_{B}^{t}, \theta^{*}\right)$ at the steady-state level $\widehat{W}\left(\theta^{*}\right)$, is different from zero; (ii) for any $W_{B}^{t} \leq \widehat{W}\left(\theta^{*}\right)$, the credit constraint remains binding at $W_{B}^{t+1}\left(W_{B}^{t}, \theta^{*}\right)$, then for $\theta$ in a non-empty interval in the neighbourhood of $\theta^{*}$, there exists at least one stable and non-degenerate two-cycle for the dynamic schedule $W_{B}^{t+1}\left(W_{B}^{t}, \theta\right)$.
} 
we examine this possibility assuming that entrepreneurs are infinitely lived and show that it is indeed the case. ${ }^{17}$ For simplicity we restrict ourselves to the case where the production technology is of the CES type and in addition we assume $e=0$. We also assume an inelastic supply of the country-specific factor. It is useful to denote the rate of return by $M^{t}=\Pi^{t} / W_{B}^{t}$. Then, as already shown in the previous subsection, whenever $\psi\left(p^{t}\right)>r$, we have: $\Pi^{t}=\left\{(1+\mu) \psi\left(p^{t}\right)-r \mu\right\} W_{B}^{t}=M^{t} W_{B}^{t}$.

We begin with the log-utility case, where each investor maximizes:

$$
\max \quad \sum_{t=0}^{\infty} \beta^{t} \log C_{B}^{t} \quad \text { s.t. } \quad C_{B}^{t}=\Pi^{t}-W_{B}^{t+1}
$$

where $C_{B}^{t}$ is entrepreneurs' consumption at date $t$ and $\beta$ is the discount factor, with $\beta<1$. We also assume that $\beta r<1$. This assumption implies that consumers are sufficiently impatient that the steady state wealth level does not lie in the unconstrained region.

The first order conditions for this maximization give us:

$$
\frac{C_{B}^{t+1}}{C_{B}^{t}}=\beta M^{t+1}
$$

This in turn implies that the solution to this programming problem takes the form:

$$
C_{B}^{t}=\xi \Pi^{t}
$$

To see this, let us a priori assume that there exists a solution of the form $C_{B}^{t}=\xi \Pi^{t}$, for all $t$. Then we must have: $C_{B}^{t+1}=\beta M^{t+1} \xi \Pi^{t}$. Moreover, since $C_{B}^{t+1}=\xi \Pi^{t+1}$, we must also have: $C_{B}^{t+1}=\xi M^{t+1} W_{B}^{t+1}=\xi M^{t+1}(1-\xi) \Pi^{t}$. These two expressions for $C_{B}^{t+1}$ are identical if and only if $\xi=1-\beta$. Therefore $C_{B}^{t}=(1-\beta) \Pi^{t}$ is one solution to the above dynamic programming problem. Now, given that this dynamic problem is strictly convex and that $\beta<1$, it is actually the unique solution to that problem. ${ }^{18}$

\footnotetext{
${ }^{17}$ Contracts are still assumed to last one period due to commitment problems.

${ }^{18}$ Woodford (1989) uses a similar result in a related context.
} 
Therefore the simple proportional savings rule we assumed in the previous subsections is actually optimal in the $\log$ utility case when $\alpha=1-\beta$ and $e=0$. Consequently, all previous results, in particular on the possibility of long-run volatility or the dynamic effects of shocks, apply automatically to that case.

Consider next the more general case where instantaneous utility is given by: $u\left(C_{B}\right)=$ $C_{B}^{1-\rho} /(1-\rho)$, where $1 / \rho$ is the elasticity of intertemporal substitution and $\rho>0$. Then domestic entrepreneurs solve:

$$
\max \sum_{t=0}^{\infty} \beta^{t} u\left(C_{B}^{t}\right) \quad \text { s.t. } \quad C_{B}^{t}=\Pi^{t}-W_{B}^{t+1}
$$

The first order conditions for this problem give us:

$$
\frac{C_{B}^{t+1}}{C_{B}^{t}}=\left(\beta M^{t+1}\right)^{\frac{1}{\rho}}
$$

It is clear from equation (15) that the ratio $\frac{C_{B}^{t+1}}{C_{B}^{t}}$ approaches 1 as $\rho$ increases. This implies that an increase in $\rho$ (a reduction in the elasticity of intertemporal substitution) reduces consumption changes and gives correspondingly larger intertemporal savings changes, i.e., savings become more pro-cyclical over time. This, in turn, will tend to amplify the cycle as the price of the country-specific input increases more sharply during a boom. True, to the extent that the returns to savings are higher when the economy is in a slump (slumps are typically followed by periods with high investment profitability), there should be a greater tendency to save more in a slump, thereby attenuating the cyclical variations. However, this latter effect is weaker, the higher the cost of intertemporal substitution (i.e., with a larger $\rho$ ).

To assess the overall effect of a change in the elasticity of intertemporal substitution on volatility, it is instructive to replace $C_{B}^{t}$ by $\Pi^{t}-W_{B}^{t+1}$ in (15), giving a dynamic relationship:

$$
W_{B}^{t+1}=\frac{\left(\beta M^{t+1}\right)^{\frac{1}{\rho}}}{M^{t+1}+\left(\beta M^{t+1}\right)^{\frac{1}{\rho}}} \Pi^{t}+\frac{1}{M^{t+1}+\left(\beta M^{t+1}\right)^{\frac{1}{\rho}}} W_{B}^{t+2}
$$


Entrepreneurs' wealth available for next period is now a weighted average of past profits and expected future wealth. While this second order (highly non-linear) difference equation does not lend itself to analytical solutions, it can be resolved numerically as we show in the next section.

\section{Assessing Plausibility: Some Simulation Results}

The main purpose of this section is to ask whether the analytical conclusions derived in the previous section are empirically plausible. The simulation results in this section are again focused on the possibility of - and the conditions for - long run volatility in economies at intermediate levels of financial development. ${ }^{19}$

Due to space constraints, we shall only discuss simulations for some of the cases discussed in Section 2. We assume infinitely-lived entrepreneurs, a CES production function, and the possibility of increasing the elasticity of supply of the country-specific factor. We present our simulation results by successively varying three parameters: i) the elasticity of substitution between capital and the other factor in the production function, measured by $\theta$; ii) the intertemporal elasticity of substitution $1 / \rho$; (iii) the elasticity of country-specific factor supply as measured by $\nu$. The other parameters are taken to be constant in these simulations, and we fix them at empirically plausible values. We set the gross interest rate $r=1.02$ and the productivity factor $A=1.5$. Whenever it is fully inelastic we set the total supply of the immobile factor $Z=100$ and its weight in the production function $\gamma=1$ (these two parameters have little influence on the simulation results). The discount rate of entrepreneurs is $\beta=0.9$, a value implying that domestic entrepreneurs are impatient relative to the interest rate. Finally, we set the credit multiplier $\mu=4$, a value implying a cash flow-capital ratio of 0.2 when firms

\footnotetext{
${ }^{19}$ When looking at the real world, the distinction between persistent oscillations that eventually die out, and those that never die out, may not be so important as our analysis suggests. This is because in reality, even if oscillations eventually die out, there are always shocks that start them off again.
} 
are credit-constrained, a plausible number even for US firms (see Fazzari, Hubbard, and Petersen (1988)). The values considered for $\theta$ lie between -0.5 and -4 ; those for $\nu$ lie between 4.33 and 7.66 corresponding to elasticities $(1 /(\nu-1))$ of 15 and 30 percent; and those for $\rho$ are between 0.5 and 10 .

In each case, we consider the dynamic impact on output of a negative shock that makes wealth fall by $1 \%$ below the steady-state wealth. We normalize output so that it is initially equal to 100 and we look at the dynamic evolution of output over 30 periods after the shock. Figures 3 and $4 \mathrm{c}$ and $4 \mathrm{~d}$ display the simulations in the log utility case where $\rho=1$. As argued in subsection 2.5, this case is equivalent to the constant savings rate economy analyzed in the previous subsections. ${ }^{20}$

Figure 3 presents the log utility case with a fixed supply of the country specific factor. The diagrams show four cases corresponding to different values of $\theta$, each leading to a different dynamic path. In Figure $3 \mathrm{a}$, where $\theta=-0.5$, there is no instability and output converges smoothly to its initial level. When $\theta$ decreases to -1.5 (Figure $3 \mathrm{~b}$ ), output still converges but includes oscillations.

Figure $3 \mathrm{c}$ shows a two-cycle, which arises when $\theta=-2$. Finally, when $\theta=-4$ (Figure 3d), more complex dynamics arise due to 'regime switching': large increases in wealth lead the system to the unconstrained region (the third segment in Figures 1 and 2), but the system returns to the constrained region since $\beta r<1$. Notice that the fluctuations in $3 \mathrm{c}$ and $3 \mathrm{~d}$ are larger than the initial shock, so that small shocks are amplified (actually infinitesimal shocks would lead to similar fluctuations).

In Figures $4 \mathrm{a}$ and $4 \mathrm{~b}$, we assume that $\theta=-4$ with an inelastic supply of the countryspecific factor, while we depart from log utility by varying the intertemporal elasticity

\footnotetext{
${ }^{20}$ Note that the simulation technique differs between the constant savings rate case and the log-utility case with infinitely lived and forward-looking entrepreneurs. In the former case, we simply need to run a first order difference equation with given initial wealth level. In the latter case, as shown at the end of subsection 2.5, the dynamic system is described by a forward-looking second order difference equation which requires that we compute the initial consumption level for given initial wealth (e.g., using a shooting algorithm). When $\rho=1$, however, the two methods generate exactly the same dynamics.
} 
parameter $\rho$. With a lower elasticity of intertemporal substitution, $\rho=10$, the system tends to be even more unstable and switches more easily across regimes. When entrepreneurs are more ready to substitute intertemporally, which in this figure corresponds to the case where $\rho=0.5$, regime switches are less frequent. The most important conclusion from Figure 4, however, is that the long-run instability results established under constant savings rates (or with optimal intertemporal savings in the log utility case), carry over to a wide range of elasticities of intertemporal substitution.

Finally, in Figures $4 \mathrm{c}$ and $4 \mathrm{~d}$ we show simulations with an elastic supply of the country-specific factor, assuming $\theta=-4$ and $\log$ utility. Obviously, with an elastic supply there is less scope for fluctuations. For example, Figure $4 \mathrm{~d}$ shows that with a supply elasticity of 30 percent fluctuations die out rapidly. However, with an elasticity of 15 percent, which appears reasonable in the short run, we still have fluctuations with a two-cycle.

Thus, even though our model is highly stylized, long-run output volatility and/or large amplification of shocks occur for empirically reasonable parameter values and are not confined to one particular functional form.

\section{Financial Liberalization and Instability}

The previous analysis shows that a fully open economy with imperfect credit markets can exhibit volatility or a cycle. We show in this section that the same economy can be stable if it is closed to capital flows or if only foreign investment (FDI) is allowed. Thus, a full liberalization to capital movements may destabilize an economy: while it stabilizes the real interest rate, it also amplifies the fluctuations in the price of the country-specific factor. This in turn, increases the volatility in firms' cash-flows and therefore aggregate output. We first consider the case of an economy that opens up to foreign lending. Then, we examine the case of FDI, where foreign investors are equity holders and are 
fully informed about domestic firms. Even though the results are valid with general production functions, we present the Leontief case for pedagogical reasons.

\subsection{Liberalizing Foreign Lending}

We consider an economy with low domestic savings, with the Leontief technology specified in Section 2.1, and we first assume that this economy is not open to foreign borrowing and lending (this closed economy is described in details in Appendix B). In that case, at each date, the current wealth of domestic lenders $W_{L}$ matters since domestic investment is constrained by domestic savings $W_{B}+W_{L}$. Now suppose that the initial levels of wealth held by entrepreneurs and domestic lenders, $W_{B}$ and $W_{L}$ respectively, are sufficiently small so that initially $p^{0}=0$ This corresponds to a situation where domestic entrepreneurs cannot exhaust the supply of country-specific inputs. Let us also assume that at date 0 domestic savings $W_{B}^{0}+W_{L}^{0}$ are less than the investment capacity $(1+\mu) W_{B}^{0} \cdot{ }^{21}$ If $\mu>1$ there will then be excess investment capacity in following periods as long as $p^{t}$ remains equal to zero. To see this, note that the domestic interest rate $r^{t}$, determined in a closed economy by the comparison between $W_{L}^{t}$ and $\mu W_{B}^{t}$, is such that entrepreneurs are indifferent between borrowing and lending, that is: $r^{t}=\frac{1}{a}$ in the Leontief case. Therefore, if $p^{t}=0$ and $W_{L}^{t}<\mu W_{B}^{t}$, we have:

$$
\begin{aligned}
W_{B}^{t+1} & =(1-\alpha)\left[e+\frac{1}{a} W_{B}^{t}\right] \\
\text { and } W_{L}^{t+1} & =(1-\alpha)\left[e+\frac{1}{a} W_{L}^{t}\right]
\end{aligned}
$$

so that $W_{L}^{t}<\mu W_{B}^{t}$ implies that: $W_{L}^{t+1}<\mu W_{B}^{t+1}$ and therefore $r^{t+1}=\frac{1}{a}$. In Appendix $\mathrm{B}$ we provide sufficient conditions under which $p^{t}=0$ and $r^{t}=\frac{1}{a}$ for all $t$. Under these conditions, entrepreneurs' wealth will grow as the (low) rate $\frac{1-\alpha}{a}$, since it is constrained by the (low) level of domestic savings, and the $W_{B}^{t+1}\left(W_{B}^{t}\right)$ schedule will intersect the $45^{0}$

\footnotetext{
${ }^{21}$ If $\mu W_{B}<W_{L}$, opening up the economy to foreign lending would make no difference: since the investment capacity of domestic entrepreneurs cannot even absorb domestic savings, there is no need for foreign lending in this case.
} 
line on its first branch along which $p^{t}=0$. This, in turn, implies that there will be no persistent fluctuations in this closed economy.

What happens if this economy is fully opened up to foreign borrowing and lending? The interest rate will be fixed at the international level $r$. By itself, this could only help stabilize any closed economy that otherwise might (temporarily) fluctuate in reaction to interest rate movements. However, the opening up of the economy to foreign lending also brings net capital inflows as investors satisfy their excess funds demand in international capital markets. The corresponding rise in borrowings in turn increases the scope for bidding up the price of the country-specific factor, thereby inducing permanent fluctuations in $p, W_{B}$ and aggregate output.

Figure 5 presents an illustration of a liberalization in the Leontief case. The wealth schedule shifts up after a capital account liberalization. $\widehat{W}_{B}$ refers to the stable steadystate level of borrowers' wealth before the economy opens up to foreign borrowing and lending. After the liberalization $W_{B}$ progressively increases as capital inflows allow investors to increase their borrowing, investments and profits. During the first two periods following the liberalization, the demand for the country-specific factor remains sufficiently low that $p=0$. In period $3\left(\right.$ at $\left.W_{B}^{3}\right) p$ increases but we still have growth. However, in period 4 (at $\left.W_{B}^{4}\right)$ the price effect of the liberalization becomes sufficiently strong as to squeeze investors' net worth, thereby bringing on a recession. At that point, aggregate lending drops, capital flows out and the real exchange depreciates ( $p$ drops). The resulting gain in competitiveness allows firms to rebuild their net worth so that growth can eventually resume. The economy ends up experiencing permanent fluctuations of the kind described in the previous section.

We should stress that the dynamics in Figure 5 occurs only for intermediate levels of financial development. As we argued in Section 2, with a large $\mu$ there is no volatility in 
an open economy, as it is the third segment of the curve that cuts the $45^{\circ}$ line. ${ }^{22}$ When $\mu=0$, financial opening will not help investment and no capital inflow will occur, so there will be no upward pressure on the price of the country-specific input. ${ }^{23}$ The above example therefore suggests that it might be desirable for a country to increase its $\mu$, i.e., to develop its domestic financial sector before fully opening up to foreign lending.

\subsection{Foreign Direct Investment}

Whilst a full liberalization to foreign lending can have destabilizing effects on economies with intermediate levels of financial development, those economies are unlikely to become volatile as a result of opening up to foreign direct investment alone. We distinguish FDI from other financial flows by assuming that it is part of firms' equity and that FDI investors have full information about firms. ${ }^{24}$ Furthermore, we first concentrate on the benchmark case where the supply of FDI is infinitely elastic at some fixed price greater than the world interest rate, say equal to $r+\delta .^{25}$

Starting from a situation in which domestic cash flows are small so that domestic investment cannot fully absorb the supply of country-specific factors, foreign direct investors are likely to enter in order to profit from the low price of the country-specific factors. This price will eventually increase and may even fluctuate as a result of FDI. But these price fluctuations will only affect the distribution of profits between domestic and foreign investors, not aggregate output. For example, in the Leontief case with FDI, aggregate output will stabilize at a level equal to the supply of factor resources $Z$, whereas the same economy may end up being destabilized if fully open to foreign

\footnotetext{
${ }^{22}$ When several developed countries did liberalize their capital movements in the 1970s and 1980s periods of high instability could not be observed.

${ }^{23}$ This may be the case in some of the poorer African and Asian countries.

${ }^{24}$ Typically, measured FDI implies participations of more than $10 \%$ in a firm's capital so this appears to be a reasonable assumption. Razin et al (1998) make a similar distinction about FDI.

${ }^{25}$ This, in turn, implies that in our model FDI is a substitute to domestic investment. The effects of FDI on macroeconomic volatility when domestic and foreign investments are complementary, are discussed at the end of this section.
} 
portfolio investment (i.e., to foreign lending).

Consider a closed Leontief economy open to foreign direct investment only. Assume also that $W_{L}$ is large enough so that firms can still borrow their desired amount domestically (otherwise investment is still constrained by savings and the scope for fluctuations is much smaller). Then FDI will flow into the economy as long as the rate of return on that investment remains greater than or equal to $r+\delta$. Thus, if $F$ denotes the net inflow of direct investment, in equilibrium we obtain the free-entry condition:

$$
F>0 \Rightarrow R=r+\delta
$$

where $R=\frac{y-\widetilde{r} L}{W_{B}+F}$ is the net rate of return on foreign direct investment and $\widetilde{r}$ is the domestic interest rate. If domestic savings are less than the investment capacity of domestic entrepreneurs (i.e., $W_{L}<\mu W_{B}$ ), we would have $\widetilde{r}=\frac{1}{a}$. However, as domestic savings exceed the investment capacity of domestic entrepreneurs, $\widetilde{r}=\underline{\sigma}$, where $\underline{\sigma}$ is the return of an alternative, inefficient, storing technology (as in Aghion, Banerjee, and Piketty (1999)). In a closed economy, lenders will invest their excess savings in this technology.

Assume that $R>r+\delta$ as long as $p=0$ (this implies $r+\delta<\frac{1}{a}(1+\mu)-\mu \underline{\sigma}$ ), so that there will be a positive flow of FDI as long as $p=0$. Using the fact that $L=\mu\left(W_{B}+F\right)$ and that $y=Z$ when $p>0$, we can rewrite the above free-entry condition as:

$$
(r+\delta)\left(W_{B}+F\right)=Z-\mu \underline{\sigma}\left(W_{B}+F\right)
$$

This, together with the price equation (3), implies that:

$$
p=\frac{1+\mu}{r+\delta+\underline{\sigma} \mu}-a,
$$

which in turn defines gives a stable value for $p$. Thus, even though FDI leads to a price increase it does not generate price and output volatility.

Consider now an economy which has already been opened up to foreign borrowing and lending at rate $r$, that is to foreign portfolio flows only, and which, as a result 
has become volatile as in the example depicted in Figure 5. What will happen if this economy is now also opening up to FDI? By the same reasoning as before, opening up to FDI will stabilize the price of the country-specific factor at level $p^{*}$ such that:

$$
(r+\delta)\left(W_{B}+F\right)=Z-r \mu\left(W_{B}+F\right) .
$$

This again will eliminate investment and output volatility in this economy (assuming that initially the country is attracting FDI). In other words, if there are no limitations on FDI inflows and outflows (and FDI involves complete information on domestic firms), the price of the country-specific factor and therefore aggregate domestic GDP or GNP will remain constant in equilibrium.

The reason why FDI acts as a stabilizing force is again that, unlike foreign lending, it does not depend on the creditworthiness of the domestic firms, and furthermore it is precisely during slumps that foreign direct investors may prefer to come in so as to benefit from the low price of the country-specific factor.

What happens if foreign direct investment is complementary to domestic direct investment, that is, to $W_{B}$ ? Such complementarity may be due to legal restrictions whereby the total amount of FDI cannot be greater than a fixed fraction $x$ of domestic investors' wealth $W_{B}$, or it may stem from the need for local investors to enforce dividend payments or to help exert control. Appendix B shows that foreign direct investments subject to complementarity requirements of the form $F \leq x W_{B}$, may sometimes de-stabilize an emerging market economy. Indeed, in contrast to the unrestricted FDI case analyzed above, such direct investments ultimately will fall during slumps, that is, when investors' wealth $W_{B}^{t+1}$ is experiencing a downturn. Downturns will also typically be deeper than in absence of FDI since, by amplifying the increase in $p^{t}$ during booms, FDI increases production costs and thus accentuates the credit-crunch induced on firms. Thus, whilst unrestricted FDI has a stabilizing effect on an open emerging market economy, opening such an economy to restricted FDI may actually have the 
opposite effect.

\section{Conclusions}

Our model provides a simple and tractable framework for analyzing financially-based crises in economies which are at an intermediate level of financial development. The story we tell is based on some very basic features of these economies, in contrast with other more institutionally-based theories which invoke moral hazard among lenders, herd behavior among investors, etc. This is not to say that our model is inconsistent with this class of theories - in fact in a previous version of this paper we argued at some length that there are interesting interactions between our model and those theories. ${ }^{26}$ However, our model does suggest a somewhat different policy response: slumps should be seen as part of a normal process in economies like these which are both at an intermediate level of financial development and in the process of liberalizing their financial sectors. We should therefore not over-react to the occurrence of financial crises, especially in the case of emerging market economies. In particular, hasty and radical overhauling of their economic system may do more harm than good. ${ }^{27}$

Second, policies allowing firms to rebuild their credit worthiness quickly will at the same time contribute to a prompt recovery of the overall economy. In this context it is worth considering the role for monetary policy and, more generally, for policies affecting the credit market. Whilst our model in its present form cannot be directly used for

\footnotetext{
${ }^{26}$ In the previous version we also show that uncertainty and firms defaults can easily be introduced in the model. We note that bankruptcy costs will significantly deepen the slumps only in those economies facing credit constraints.

${ }^{27}$ Indeed, if our model is right, the slump sets in motion forces which, even with little interference, should eventually bring growth back to these economies. The risk is that by trying to overhaul the system in a panic, one may actually undermine those forces of recovery instead of stimulating them. This is not to deny that there is a lot that needs changing in these economies, especially on the institutional side with the establishment and enforcement of disciplinary rules in credit and banking activities. For example, in the context of our model, banks may typically engage in preemptive lending to speculators in domestic inputs and/or to producers during booms. This in turn will further increase output volatility whenever inadequate monitoring and expertise acquisition by banks increases aggregate risk and therefore the interest rate imposed upon domestic producers.
} 
this purpose since money is neutral (and in any case the interest rate is fixed by the world interest rate), it can be extended to allow for both monetary non-neutrality and a less infinitely elastic supply of foreign loans (see Aghion-Bacchetta-Banerjee (2000a, b)). Once we take our framework in this direction it quickly becomes clear that a low interest rate policy is not necessarily the right answer even in a slump induced by a credit crunch. The problem is that while such an interest rate reduction may help restore the firms' financial health (and therefore their investment capacity), the net obligations of those who have borrowed in foreign currency will also rise if it leads to a devaluation of the domestic currency. Therefore, the optimal interest rate policy ex post during a financial crisis cannot be determined without knowing more about the details of the currency composition of the existing debt obligations of domestic enterprises.

This emphasis on creditworthiness as the key element in the recovery from a slump, also suggests that a policy of allowing insolvent banks to fail may in fact prolong the slump if it restricts firms' ability to borrow (because of the comparative advantage of banks in monitoring firms' activities ${ }^{28}$ ). If banks must be shut down, there should be an effort to preserve their monitoring expertise on the relevant industries. Moreover, to the extent that the government has to spend resources on restructuring and cleaning-up after a spate of bankruptcies, it should avoid raising taxes during a slump since doing so would further limit the borrowing capacity of domestic entrepreneurs and therefore delay the subsequent recovery.

Third, our model also delivers ex ante policy implications for emerging market economies not currently under a financial crisis. In particular: (i) an unrestricted financial liberalization may actually destabilize the economy and engender a slump that would otherwise not have happened. If a major slump is likely to be costly even in the long-run (because, for example, it sets in process destabilizing political forces), fully lib-

\footnotetext{
${ }^{28}$ See Diamond (1984).
} 
eralizing foreign capital flows and fully opening the economy to foreign lending may not be a good idea at least until the domestic financial sector is sufficiently well-developed (that is, until the credit-multiplier $\mu$ becomes sufficiently large); (ii) foreign direct investment does not destabilize. Indeed, as we have argued above, FDI is most likely to come in during slumps when the relative price of the country-specific factor is low; furthermore, even if this price ends up fluctuating when the economy is open to FDI, these fluctuations will only affect the distribution of profits between domestic and foreign investors but not aggregate output. Therefore there is no cost a priori to allowing FDI even at low levels of financial development. ${ }^{29}$; (iii) what brings about financial crises is precisely the rise in the price of the country specific factors. If one of these factors (say, real estate) is identified to play a key role in sparking a financial crisis, it would be sensible to control its price, either directly or though controlling its speculative demand using suitable fiscal deterrents. This, and other important aspects in the design of stabilization policies for emerging market economies, await future elaborations of the framework developed in this paper.

\footnotetext{
${ }^{29}$ This strategy of allowing only FDI at early stages of financial development is in fact what most developed countries have done, in particular in Europe where restrictions on cross-country capital movements have only been fully removed in the late 1980's whereas FDI to - and between - European countries had been allowed since the late 1950's.
} 


\section{Appendix A: \\ Solving the Model with a CES Production Function}

In this Appendix we derive the results for the CES case presented in Section 2.3. Assume that $f(K, z)=y=A\left(K^{\theta}+\gamma z^{\theta}\right)^{\frac{1}{\theta}}$ where: $K=I-p z$. The first order condition with respect to $z$ gives:

$$
\left(\frac{I-p z}{z}\right)^{\theta-1}=\frac{\gamma}{p}
$$

which can be written as.

$$
\left(\frac{p}{\gamma}\right)^{\frac{1}{\theta-1}} I=z\left(1+p^{\frac{\theta}{\theta-1}} \gamma^{\frac{1}{1-\theta}}\right)=z \phi
$$

Equation (17) implies that:

$$
K^{\theta}=\left(\frac{\gamma}{p}\right) z^{\theta-1} K
$$

Substituting for $K^{\theta}$ in the expression for $y$, and then using equation (18), we get:

$$
\begin{aligned}
y & =A\left[(I-p z) \frac{\gamma}{p} z^{\theta-1}+\gamma z^{\theta}\right)^{\frac{1}{\theta}} \\
& =A\left(I \frac{\gamma}{p} z^{\theta-1}\right)^{\frac{1}{\theta}} \\
& =A I \phi^{\frac{1-\theta}{\theta}} \\
& =I \cdot \psi(p),
\end{aligned}
$$

where $\psi(p)=A \phi^{\frac{1-\theta}{\theta}}$. For future reference note that

$$
\psi^{\prime}(p)=-\frac{\phi(p)-1}{p \phi(p)} \cdot \psi(p)
$$

To compute $\frac{d W_{B}^{t+1}}{d W_{B}^{t}}$, note first that for $W_{B}^{t}<\bar{W}$, we have $I^{t}=(1+\mu) W_{B}^{t}$, since $\psi\left(p^{t}\right)>r$. This allows us to rewrite equation (4) as

$$
W_{B}^{t+1}=(1-\alpha)\left[e+\left\{(1+\mu) \psi\left(p^{t}\right)-r \mu\right\} W_{B}^{t}\right]
$$


Next, setting $z=Z$ in equation (18) and differentiating with respect to $p$ and $W_{B}$ gives us:

$$
\frac{d p}{d W_{B}}=\frac{(1-\theta) p \phi(p)}{\phi(p)-\theta(\phi(p)-1)} \frac{1}{W_{B}}
$$

Differentiating the above expression for $W_{B}^{t+1}$ and using (19), (20), and the definition of $\psi(p)$, we get

$$
\frac{d W_{B}^{t+1}}{d W_{B}^{t}}=(1-\alpha)\left[\frac{(1+\mu) \psi(p)}{\phi(p)(1-\theta)+\theta}-r \mu\right]
$$

This expression only applies when $W_{B}^{t}<\bar{W}$. For $W_{B}^{t} \geq \bar{W}$,

$$
W_{B}^{t+1}=(1-\alpha)\left[e+r W_{B}^{t}\right]
$$

and $\frac{d W_{B}^{t+1}}{d W_{B}^{t}}=(1-\alpha) r$.

At $W_{B}^{t}=0, p=0$ (from equation (18)) and therefore $\phi=1$ and $\psi=A>r$. In other words, $\bar{W}>0$ and the dynamics are described by (4). Therefore at the origin $\frac{d W_{B}^{t+1}}{d W_{B}^{t}}=$ $(1-\alpha)[(1+\mu) A-r \mu]>0$. As $W_{B}^{t}$ goes to $\infty, p$ also goes to $\infty$. As long as $\theta<0, \phi(p)$ is increasing in $p$ and goes to $\infty$ as $p$ goes to $\infty^{30}$ Moreover as $\theta<0, \psi$ is decreasing as a function of $\phi$ and goes to 0 when $\phi$ goes to $\infty$. Therefore $\frac{(1+\mu) \psi(p)}{\phi(p)(1-\theta)+\theta}$ is decreasing as function of $W_{B}^{t}$ and goes to 0 as $W_{B}^{t}$ goes to $\infty$. In other words, as long as $\theta<0$, the $W_{B}^{t+1}\left(W_{B}^{t}\right)$ schedule defined by equation (4) is single-peaked and there exists a finite value of $W^{*}$ such that it slopes down for $W_{B}^{t}>W^{*}$.

\section{Appendix B: The Analytics of Financial Liberalization}

\section{A) Liberalization to Foreign Lending}

Here, we construct an example of an economy which, in the absence of foreign borrowing and lending, would be asymptotically stable and actually converge to a permanent boom, but which becomes permanently volatile once fully open to foreign borrowing and

\footnotetext{
${ }^{30} \phi(p)=1+p^{\frac{\theta}{\theta-1}} \gamma^{\frac{1}{\theta-1}}$ and if $\theta<0$, the exponent on $p$ is always positive.
} 
lending. The analysis of the closed economy is similar to Aghion, Banerjee, and Piketty (1999).

More specifically, consider an economy in which:

(a) The production technology is Leontief with an inelastic supply of the countryspecific factor, that is: $f(K, z)=\min \left(\frac{K}{a}, z\right), a<1$, where $K=I-p \cdot z$.

(b) Financial markets are initially closed to foreign capital inflows so that the aggregate supply of funds available to domestic investors, $I^{t}$, is now equal to the min of the investment capacity $(1+\mu) W_{B}^{t}$ and of total domestic savings $W_{B}^{t}+W_{L}^{t}$. That is:

$$
I^{t}=\min \left\{(1+\mu) W_{B}^{t}, W_{B}^{t}+W_{L}^{t}\right\}
$$

(c) Initially, at time $t=0$, the investment capacity of domestic entrepreneurs exceeds the total amount of domestic savings, so that $\mu W_{B}^{0}>W_{L}^{0}$ (in the opposite case, opening up to foreign borrowing and lending would have no effect on investment and output in the domestic economy).

(d) We impose the following restrictions on the parameters of the economy:

(i) $\mu>1$

(ii) $1-\alpha<a$

(iii) $W_{L}^{0}$ and $W_{B}^{0}$ are less than $\widehat{W}=\frac{(1-\alpha) e}{1-(1-\alpha) \frac{1}{a}}$

(iv) $\widehat{W}<\frac{a}{2} Z$.

We now show that a closed economy which satisfies assumptions (a), (b), (c), (d), is stable, with constant price $p^{t} \equiv 0$ and constant interest rate $r^{t} \equiv \frac{1}{a}$, and wealth levels $W_{B}^{t}$ and $W_{L}^{t}$ which both converge monotonically to $\widehat{W}$ as $t \rightarrow \infty$.

First, assumption (c) implies that $r^{0}=\frac{1}{a}$, and it also implies that $I^{0}=W_{L}^{0}+W_{B}^{0}$; assumptions (d)-(iii) and (d)-(iv) then imply that $I^{0}<a Z$, so that $p^{0}=0$. Next, one 
can show that at any date $s, r^{s}=\frac{1}{a}$ and $p^{s}=0$. To see this, suppose that for all $s \leq t$, $r^{s}=\frac{1}{a}$ and $p^{s}=0$, and let us show that $r^{t+1}=\frac{1}{a}$ and $p^{t+1}=0$. If $r^{s}=\frac{1}{a}$ and $p^{s}=0$ for all $s \leq t$, then for all $s \leq t$ the wealth levels $W_{L}^{s+1}$ and $W_{B}^{s+1}$ satisfy the equations:

$$
W_{L}^{s+1}=(1-\alpha)\left[e+\frac{1}{a} W_{L}^{s}\right]
$$

and

$$
W_{B}^{s+1}=(1-\alpha)\left[e+\frac{1}{a} W_{B}^{s}\right] .
$$

It then follows from assumption (d)-(i), i.e., from $\mu>1$, and from assuming that $r^{t}=\frac{1}{a}$ (which implies that $\mu W_{B}^{t}>W_{L}^{t}$ ), that $\mu W_{B}^{t+1}>W_{L}^{t+1}$ and therefore $r^{t+1}=\frac{1}{a}$. Furthermore, it follows from assumption (d)-(iii) and equations (1) $)_{s}$ and (2) $)_{s}$ for $s \leq t$, that $W_{L}^{s}<\widehat{W}$ and $W_{B}^{s}<\widehat{W}$ for all $s \leq t+1$; this in turn implies that:

$$
I^{t+1}=W_{L}^{t+1}+W_{B}^{t+1}<2 \widehat{W}
$$

so that $I^{t+1}<a Z$ by assumption (d)-(iv) and therefore $p^{t+1}=0$. We have thus shown that if $r^{s}=\frac{1}{a}$ and $p^{s}=0$ for all $s \leq t$, then $r^{t+1}=\frac{1}{a}$ and $p^{t+1}=0$. Together with the fact that $r^{0}=\frac{1}{a}$ and $p^{0}=0$, this proves by induction that $r^{s}=\frac{1}{a}$ and $p^{s}=0$ for all $s$, so that the entire wealth trajectory $\left(W_{L}^{s}, W_{B}^{s}\right)$ is determined by $\left(W_{L}^{0}, W_{B}^{0}\right)$ together with the dynamic equations $(1)_{s}$ and $(2)_{s}$. But this, together with assumption (d)-(ii), implies that the equilibrium trajectory $\left(W_{L}^{s}, W_{B}^{s}\right)$ is stable, with both $W_{L}^{s}$ and $W_{B}^{s}$ converging monotonically towards $\widehat{W}$ when $t \rightarrow \infty$. Thus, a closed economy characterized by (a)-(d) will display no volatility in price, interest rate, wealth and (tradeable) output.

Now, a closed economy that satisfies (a)-(d) and therefore is stable, may end up becoming volatile if fully open to foreign borrowing and lending. For example, this will be the case if that same economy satisfies the sufficient conditions provided in Section 2.2 for the existence of two-cycles. And one can easily verify that the two sets of conditions are consistent, in the sense that there exists a non-empty set of parameters which satisfy both sets of conditions simultaneously. 


\section{B) Restricted FDI}

Let $F$ denote the current amount of FDI, and let us impose the constraint: $F \leq x W_{B}$, with the fraction $x$ being initially small. We assume that foreign investors receive their proportional share of output and that this is always larger than their reservation return $r+\delta$ (given the constraint $x$, the supply is no longer fully elastic as in the preceding case). The equilibrium price for the country-specific factor is now equal to:

$$
p^{t}=\max \left(0, \frac{(1+\mu)\left(W_{B}^{t}+F^{t}\right)-a Z}{Z}\right) .
$$

Let $L^{t}=\mu\left(W_{B}^{t}+F^{t}\right)$. Then the dynamics of investors' wealth is described by the equations:

$$
\text { (I) } \quad W_{B}^{t+1}=(1-\alpha)\left[e+\frac{1}{a}\left(W_{B}^{t}+F^{t}+L^{t}\right)-\widetilde{r} L^{t}\right]
$$

when $W_{B}^{t}$ is small and therefore $p^{t} \equiv 0$ (part 1 of the $W_{B}^{t+1}\left(W_{B}^{t}\right)$ curve), and:

$$
W_{B}^{t+1}=(1-\alpha)\left[e+\frac{Z}{1+x}-\widetilde{r} L^{t}\right]
$$

when there is excess demand for the country-specific factor and therefore $p^{t}$ becomes positive (part 2 of the $W_{B}^{t+1}\left(W_{B}^{t}\right)$ curve).

(In (I) and (II) the variable $\widetilde{r}$ denotes the domestic interest rate, which is equal to $\underline{\sigma}$ if $\mu\left(W_{B}+F\right)<W_{L}$ and to the profit rate otherwise.

For $x$ sufficiently small, we have $F^{s}=x W_{B}^{s}$ so that the above equation (II) implies a total level of direct investment (domestic and foreign) equal to:

$$
W_{B}^{t+1}+x W_{B}^{t+1}=(1-\alpha)\left[e(1+x)+Z-\tilde{r} \mu W_{B}^{t}(1+x)^{2}\right]
$$

which for $e$ small is decreasing in $x$. In particular, starting from an economy without any FDI, introducing highly constrained FDI may end up deepening the slump which it was meant to eliminate. 


\section{References}

[1] Aghion, Ph., Ph. Bacchetta, and A. Banerjee (1999), "Financial Liberalization and Volatility in Emerging Market Economies," in P.R. Agénor, M. Miller, D. Vines, and A. Weber (eds.), The Asian Financial Crises: Causes, Contagion and Consequences, Cambridge University Press, p. 167-190. Published under the wrong title "Capital Markets and the Instability of Open Economies".

[2] Aghion, Ph., Ph. Bacchetta, and A. Banerjee (2000a), "A Simple Model of Monetary Policy and Currency Crises," European Economic Review 44, 728-738.

[3] Aghion, Ph., Ph. Bacchetta, and A. Banerjee (2000b), "Currency Crises and Monetary Policy in an Economy with Credit Constraints," CEPR Discussion Paper No. 2529.

[4] Aghion, Ph., A. Banerjee, and T. Piketty (1999), "Dualism and Macroeconomic Volatility," Quarterly Journal of Economics, November, 1357-1397.

[5] Azariadis, C. and B. Smith (1998), "Financial Intermediation and Regime Switching in Business Cycles," American Economic Review 88, 516-536.

[6] Bacchetta, Ph. (1992), "Liberalization of Capital Movements and of the Domestic Financial System," Economica 59, 465-74.

[7] Bacchetta, Ph and R. Caminal (1999), "Do Capital Market Imperfections Exacerbate Output Fluctuations?," European Economic Review 44, 449-468.

[8] Bacchetta, Ph. and E. van Wincoop (2000), "Capital Flows to Emerging Markets: Liberalization, Overshooting, and Volatility," in S. Edwards (ed.), Capital Flows and the Emerging Economies - Theory, Evidence, and Controversies, The University of Chicago Press, 61-98. 
[9] Bartolini, L. and A. Drazen (1997), "When Liberal Policies Reflect External Shocks, What Do We Learn?" Journal of International Economics 42, 249-73.

[10] Bernanke, B. and M. Gertler (1989), "Agency Costs, Net Worth, and Business Fluctuations," American Economic Review 79, 14-31.

[11] Bernanke, B., M. Gertler, and S. Gilchrist (1998), "The Financial Accelerator in a Quantitative Business Cycle Framework," in J. Taylor and M. Woodford (eds), Handbook of Macroeconomics, vol. 1C, 1341-1393.

[12] Calvo, G.A., L. Leiderman, and C.M. Reinhart (1996), "Inflows of Capital to Developing Countries in the 1990s," Journal of Economic Perspectives 10, 123-39.

[13] Diamond, D (1984), "Financial Intermediation and Delegated Monitoring", Review of Economic Studies, 62, 393-414.

[14] Eichengreen, B., M. Mussa, G. Dell'Ariccia, G.M. Milesi-Ferretti, and A. Tweedie (1998), "Capital Account Liberalization: Theoretical and Practical Aspects," IMF Occasional Paper No. 172.

[15] Fazzari, S.M., R.G. Hubbard, and B.C. Petersen (1988), "Financing Constraints and Corporate Investment," Brookings Papers on Economic Activity 1:1998, 141195.

[16] Feldstein, M. and C. Horioka (1980), "Domestic Saving and International Capital Flows," Economic Journal 90, 314-29.

[17] Galvez, J. and J. Tybout (1985), "Microeconomic Adjustments in Chile during 1977-81: The Importance of Being a Grupo," World Development 13, 969-994.

[18] Gertler, M. and K. Rogoff (1990), "North-South Lending and Endogenous CapitalMarkets Inefficiencies," Journal of Monetary Economics 26, 245-66. 
[19] Gourinchas, P.-O., R. Valdés, and O. Landerretche (1999), "Lending Booms: Some Stylized Facts," mimeo, Princeton University.

[20] Guerra de Luna, A. (1997), "Residential Real Estate Booms, Financial Deregulation and Capital Inflows: an International Perspective," mimeo, Banco de México.

[21] Grandmont, J.-M. (1988), "Non-Linear Difference Equations, Bifurcations and Chaos: An Introduction," CEPREMAP Working Paper No. 8811, Paris.

[22] Holmstrom, B. and J. Tirole (1997), "Financial Intermediation, Loanable Funds and the Real Sector," Quarterly Journal of Economics CXII, 663-691.

[23] Honkapohja, S. and E. Koskela (1999), "The Economic Crisis of the 1990's in Finland," Economic Policy 14, 401-436.

[24] Hubbard, R. G. (1998), "Capital Market Imperfections and Investment," Journal of Economic Literature 36, 193-225.

[25] Johnston, R.B., S.M. Darbar, and C. Echeverria (1997), "Sequencing Capital Account Liberalizations: Lessons from the Experiences in Chile, Indonesia, Korea, and Thailand," IMF Working Paper 97/157.

[26] Krugman, P. (1979), "A Model of Balance of Payments Crises," Journal of Money, Credit and Banking 11, 311-25.

[27] Kyotaki, N. and J. Moore (1997), "Credit Cycles," Journal of Political Economy $105,211-248$.

[28] McKinnon, R.I. (1993), The Order of Economic Liberalization, The Johns Hopkins University Press.

[29] McKinnon, R.I. and H. Pill (1997), "Credible Economic Liberalizations and Overborrowing," American Economic Review (Papers and Proceedings) 87, 189-193. 
[30] de Melo, J., R. Pascale, and J. Tybout (1985), "Microeconomic Adjustments in Uruguay during 1973-81: The Interplay of Real and Financial Shocks," World Development 13, 995-1015.

[31] Mishkin, F.S. (1996), "Understanding Financial Crises: A Developing Country Perspective," Annual World Bank Conference on Development Economics, 29-62.

[32] Obstfeld, M. (1986), "Capital Flows, the Current Account, and the Real Exchange Rate: The Consequences of Liberalization and Stabilization," in S. Edwards and L. Ahamed (eds.), Economic Adjustment and Exchange Rates in Developing Countries, University of Chicago Press.

[33] Petrei, A.H. and J. Tybout (1985), "Microeconomic Adjustments in Argentina during 1976-81: The Importance of Changing Levels of Financial Subsidies," World Development 13, 949-968.

[34] Razin, A., E. Sadka, and C.-W. Yuen (1998), "A Pecking Order of Capital Inflows and International Tax Principles," Journal of International Economics 44, 45-68.

[35] Tornell, A. (1998), "Common Fundamentals in the Tequila and Asian Crises," mimeo, Harvard University.

[36] Woodford, M. (1989), "Imperfect Financial Intermediation and Complex Dynamics," in W. Barnett et al. (eds), Economic Complexity: Chaos, Sunspot, Bubbles and Nonlinearity.

[37] World Bank (1997), Private Capital Flows to Developing Countries, Policy Research Report, Oxford University Press. 


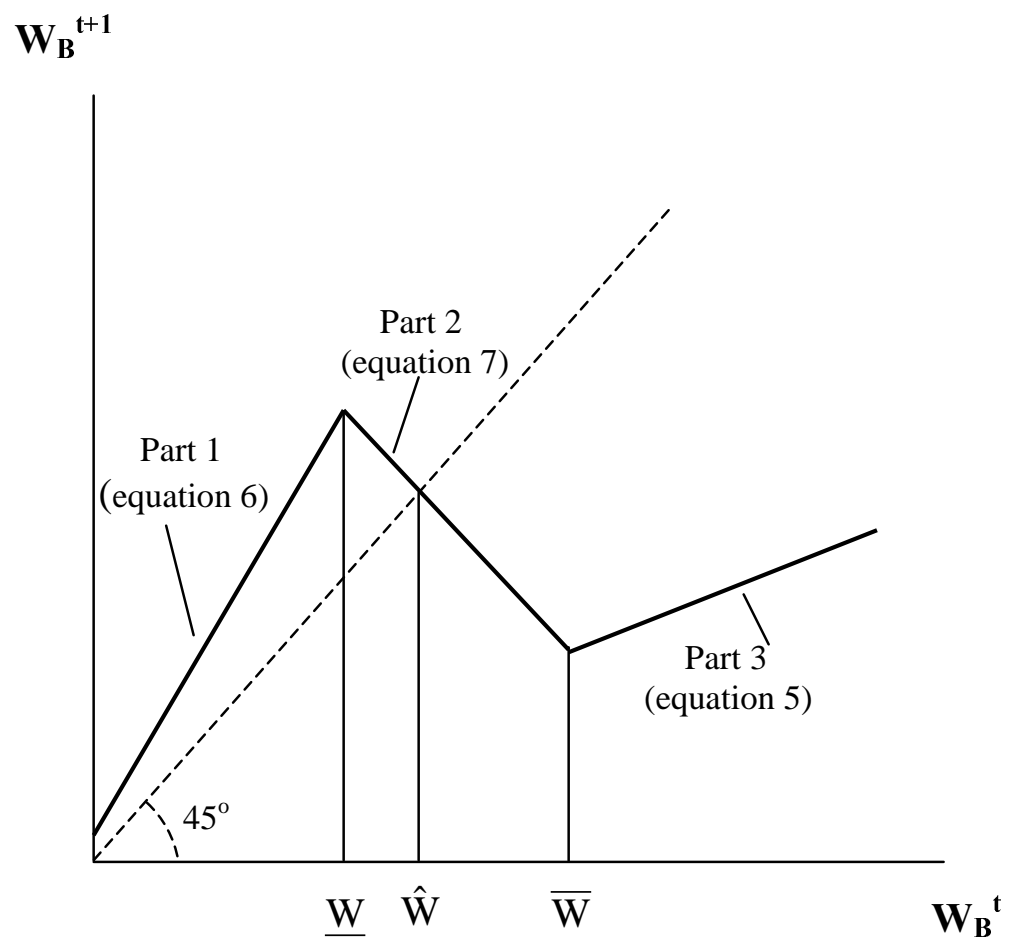

Figure 1 


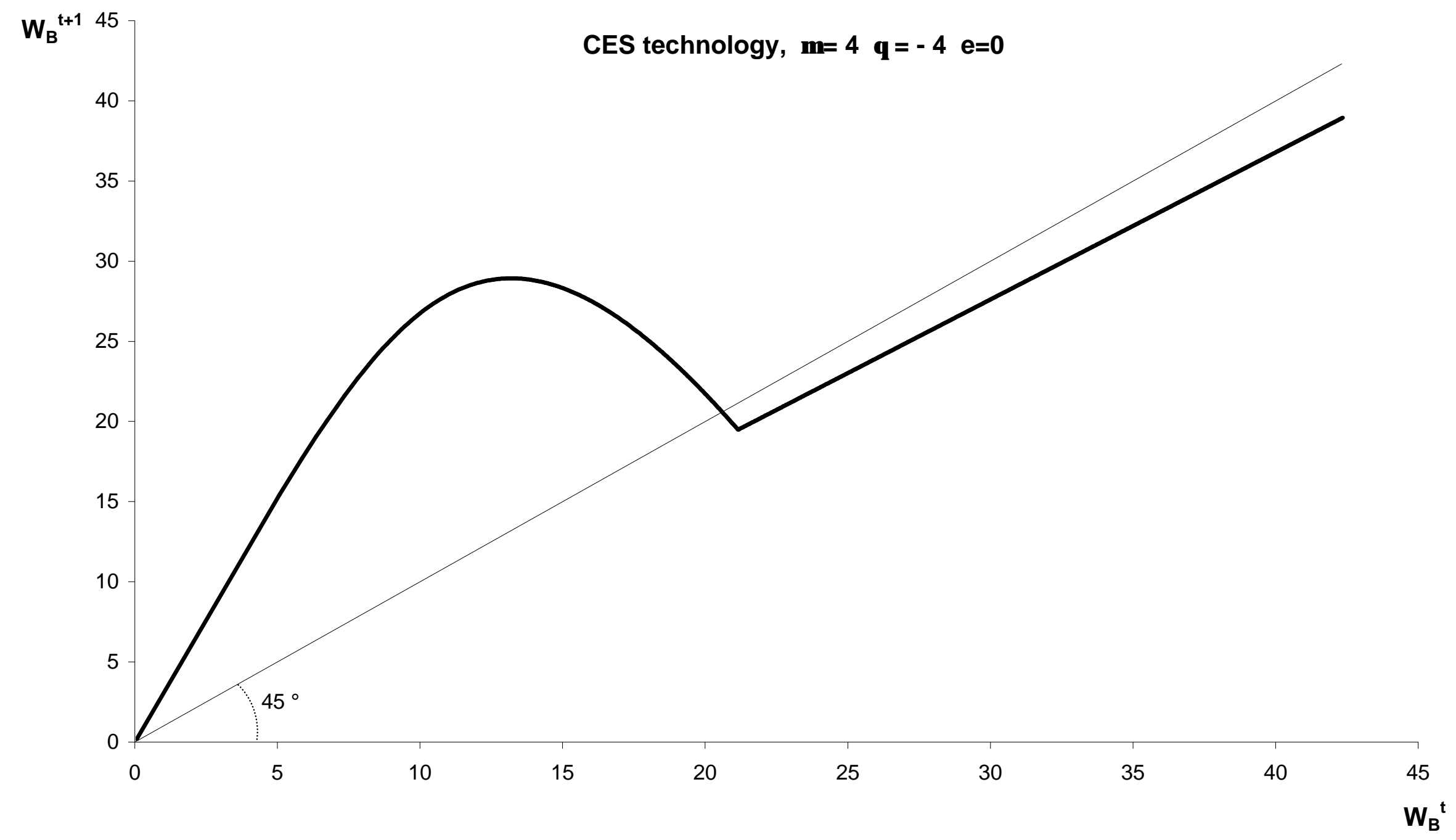

Figure 2 
Figure 3 Simulations for log utility

$3 a$

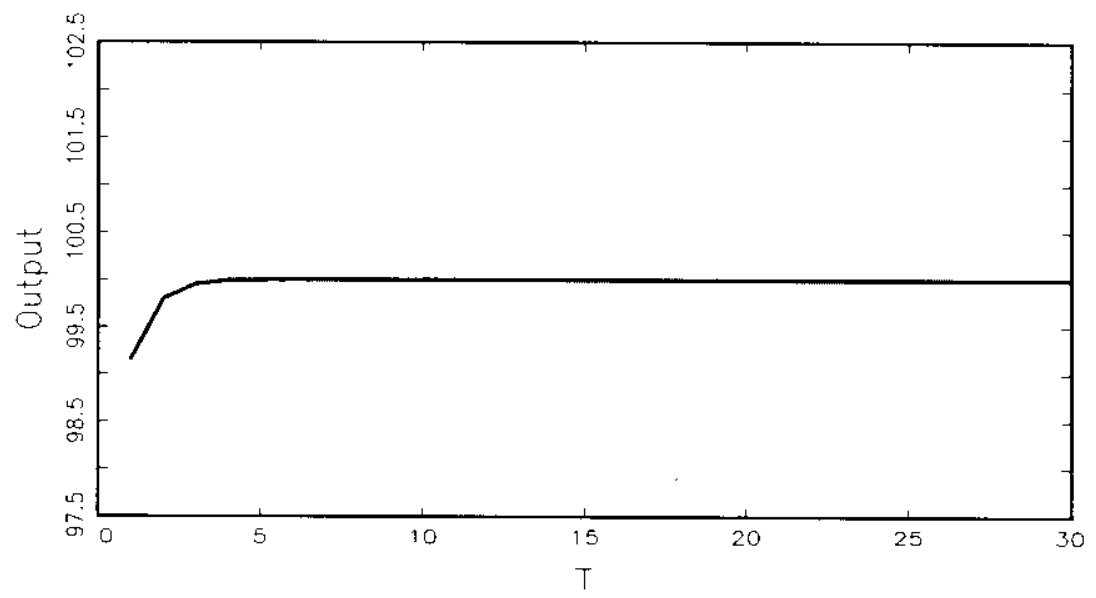

3c Theta $=-2$

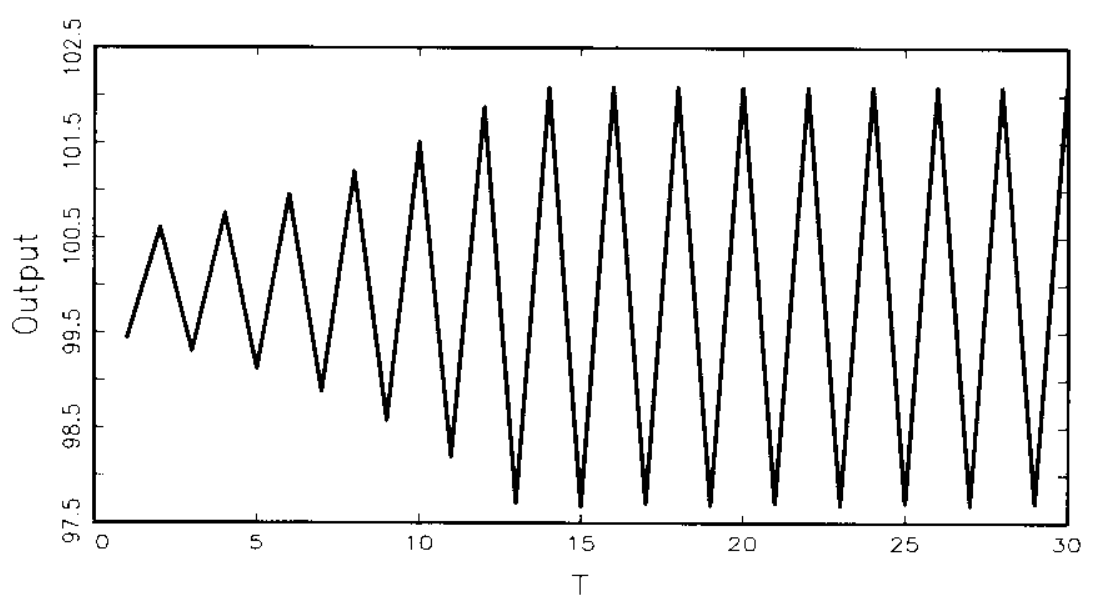

3b $\quad$ Thet $a=-1.5$

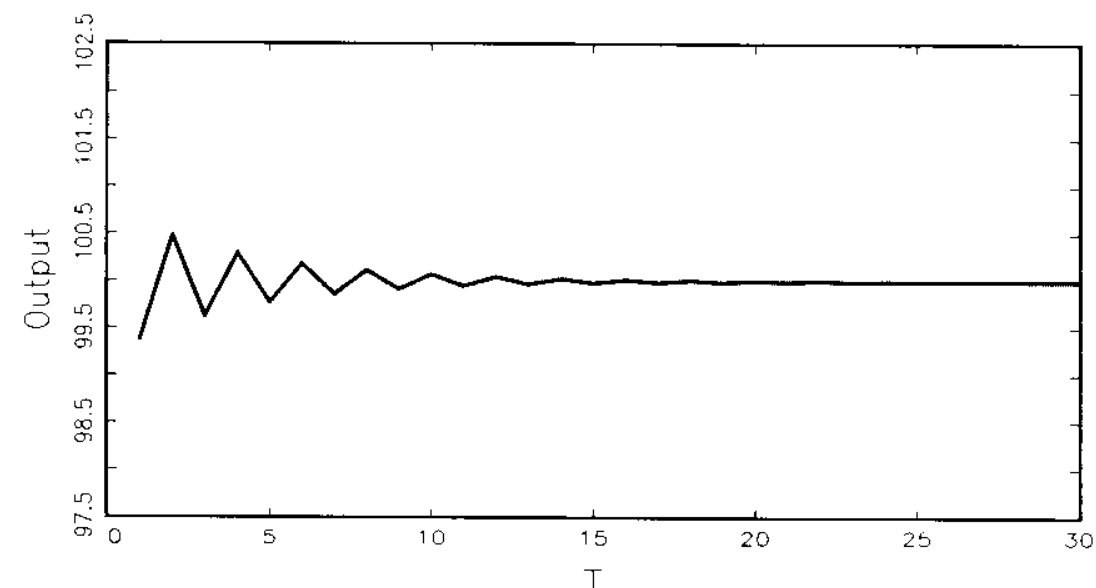

$3 d$

Thet $a=-4$

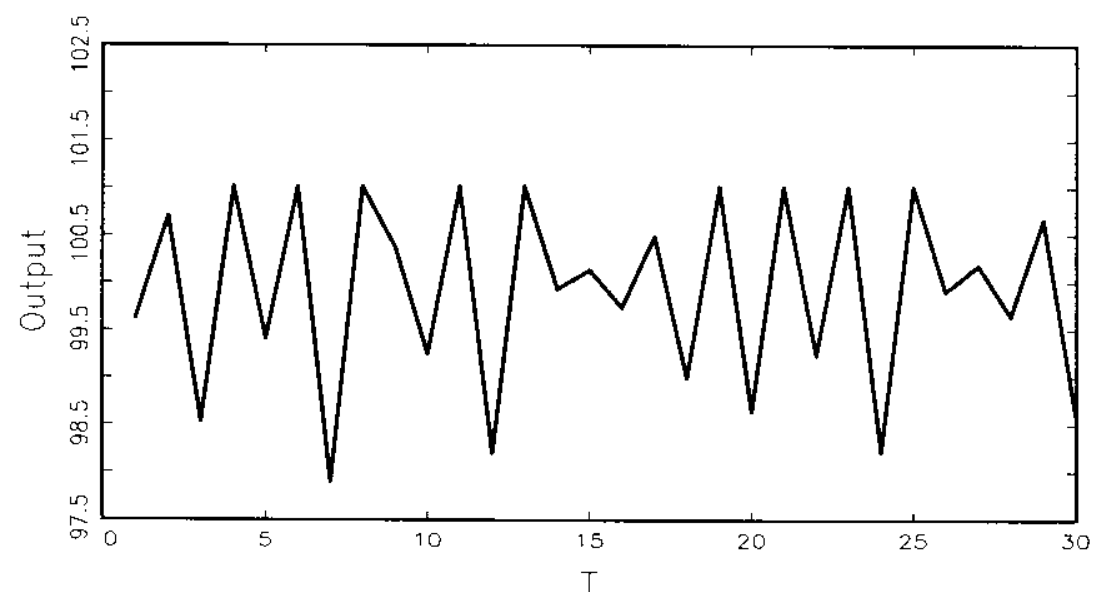

Note: see text for description 
Figure 4 Simulations

4a Thet $a=-4, \quad$ Rho $=10$

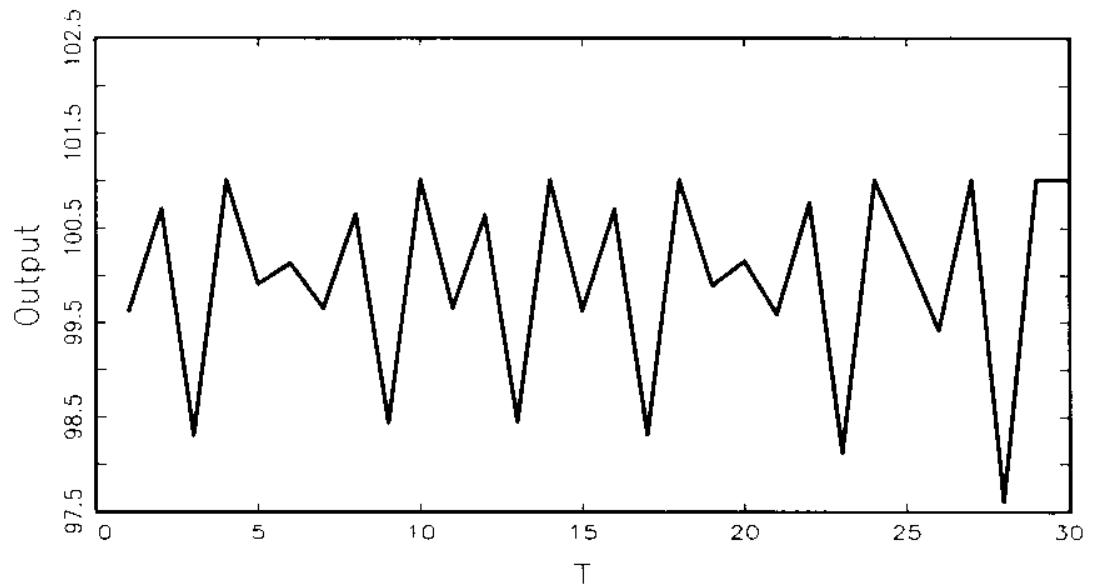

4c Supply elasticity $=15 \%$

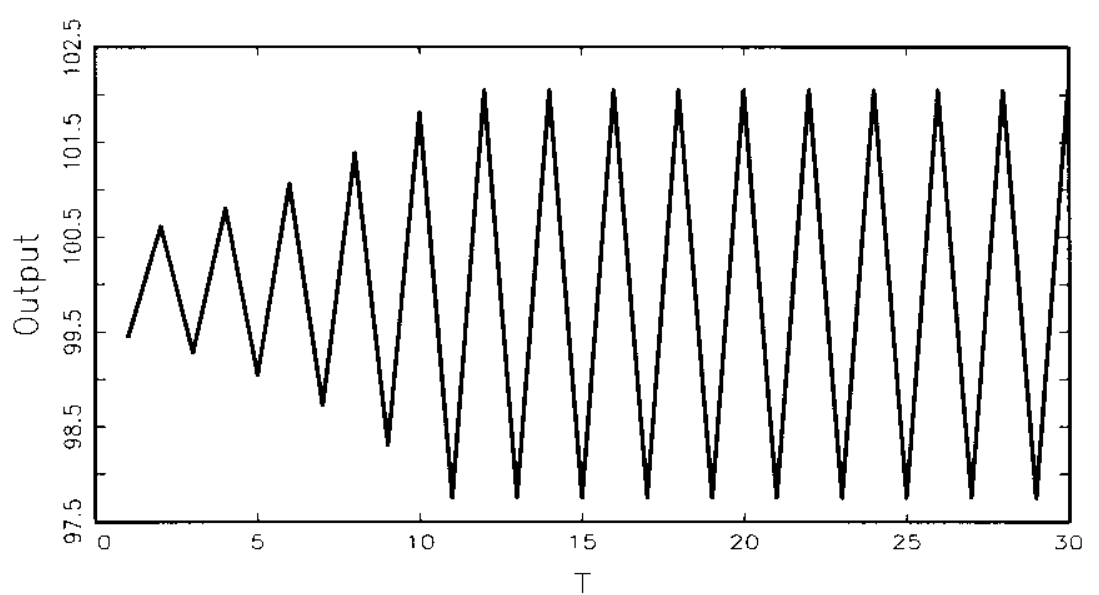

4b $\quad$ Theta $=-4$, Rho $=0.5$

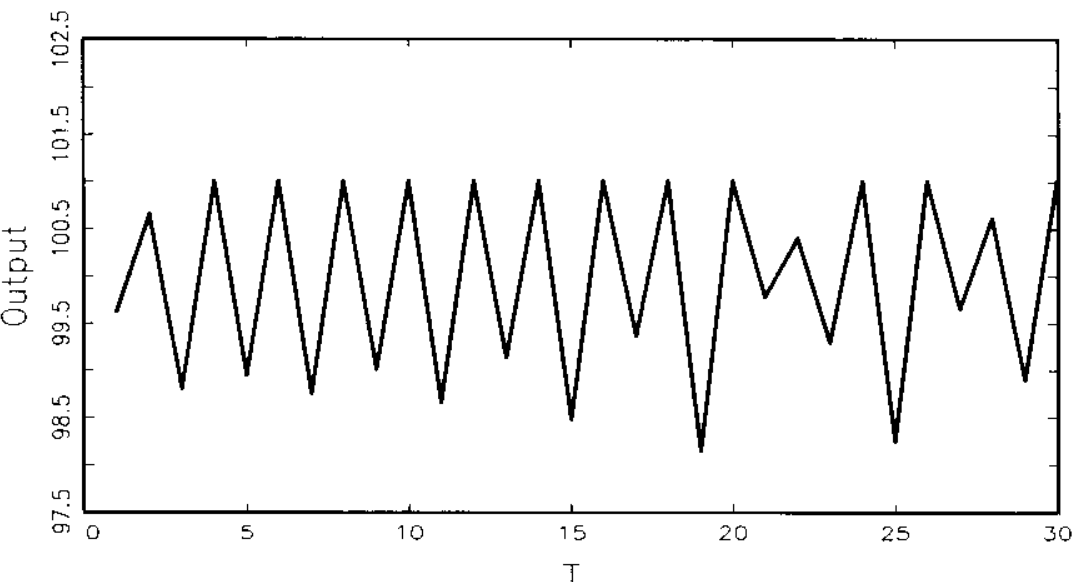

4d Supply elasticity $=30 \%$

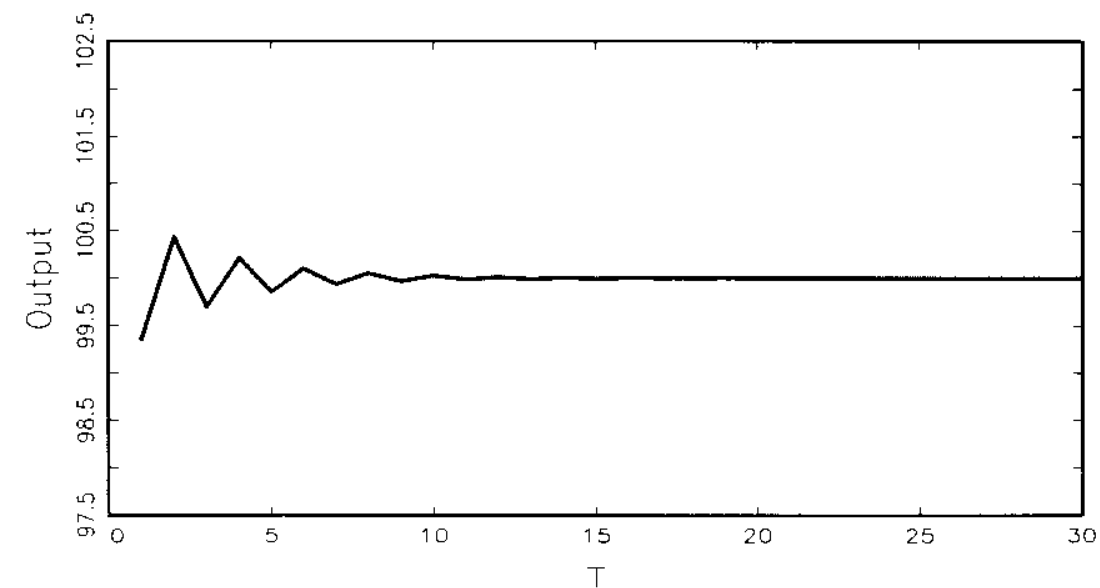

Note: see text for description 


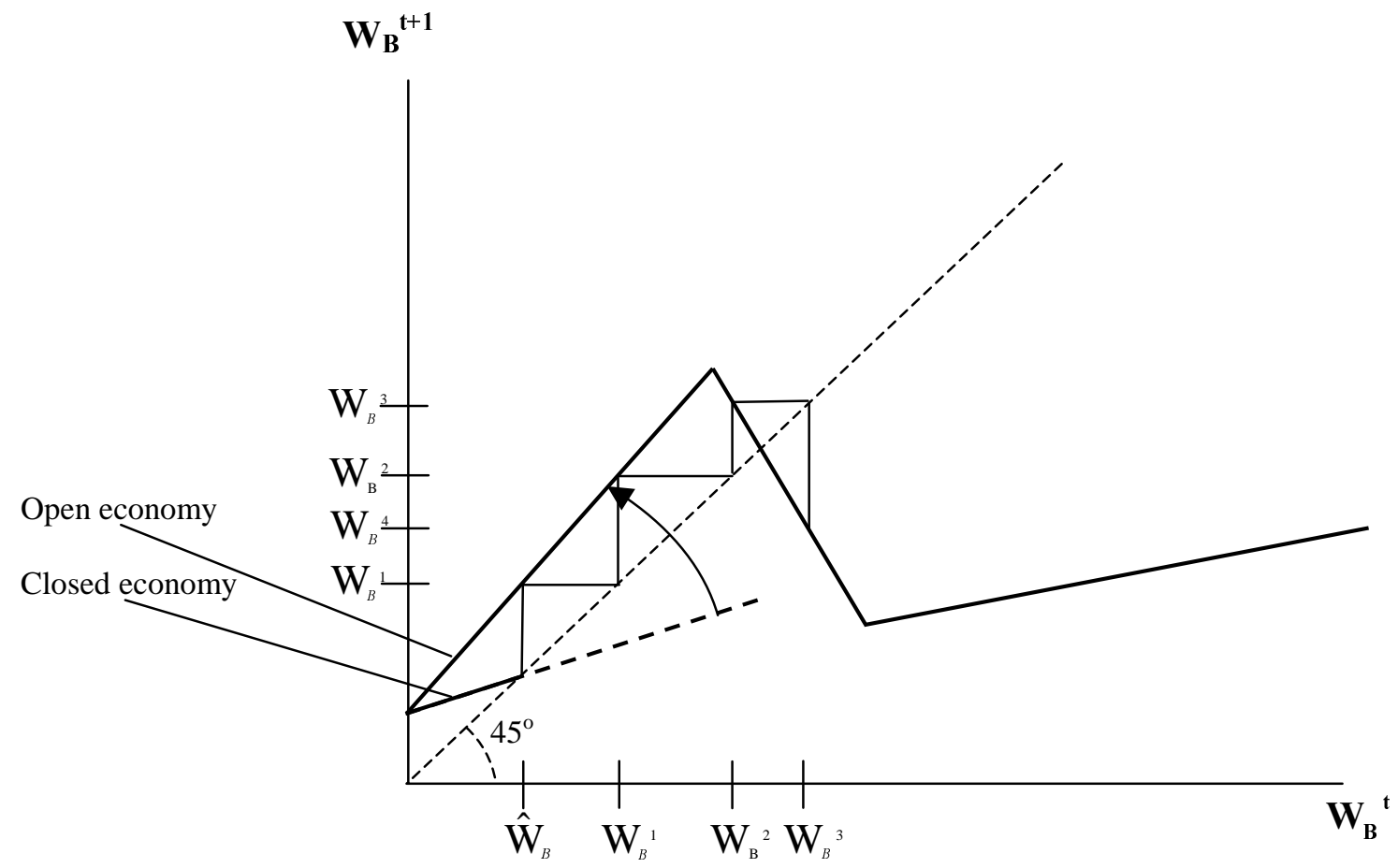

Figure 5 